\title{
Diffusion in the Ti-Al-V System
}

\author{
Greta Lindwall $^{1,2} \cdot$ Kil-Won Moon $^{1} \cdot$ Zhangqi Chen $^{3} \cdot$ Michael Mengason $^{4}$. \\ Maureen E. Williams ${ }^{1} \cdot J_{u s t i n}$ M. Gorham ${ }^{4} \cdot$ Ji-Cheng Zhao $^{3} \cdot$ Carelyn E. Campbell $^{1}$
}

Submitted: 2 May 2018/in revised form: 15 August 2018/Published online: 23 August 2018

(C) The Author(s) 2018

\begin{abstract}
Diffusion in the Ti-Al-V system is studied and a CALculation of Phase Diagrams (CALPHAD) diffusion mobility description is developed. Diffusion couple experiments are performed to obtain diffusion paths in the hcp phase at $923 \mathrm{~K}, 1023 \mathrm{~K}$ and $1123 \mathrm{~K}$. The diffusion coefficient of $V$ in the hcp-Ti phase is found to decrease with increasing $\mathrm{Al}$ alloying. A forward-simulation analysis is used to evaluate the impurity diffusion coefficient for $\mathrm{Al}$ and $V$ diffusion in the hcp Ti-V and the Ti-Al systems which are used as input in the mobility modeling. The composition dependency for the diffusion in the hcp phase in the ternary system is accounted for and a CALPHAD diffusion mobility description is obtained by directly optimizing the mobility parameters as a function of the
\end{abstract}

This invited article is part of a special issue of the Journal of Phase Equilibria and Diffusion in honor of Prof. Zhanpeng Jin's 80th birthday. The special issue was organized by Prof. Ji-Cheng (JC) Zhao, The Ohio State University; Dr. Qing Chen, Thermo-Calc Software AB; and Prof. Yong Du, Central South University.

Electronic supplementary material The online version of this article (https://doi.org/10.1007/s11669-018-0673-9) contains supplementary material, which is available to authorized users.

Greta Lindwall

gretal@kth.se

1 Materials Science and Engineering Division, National Institute of Standards and Technology, 100 Bureau Dr., Gaithersburg, MD 20899

2 Department of Materials Science and Engineering, KTH Royal Institute of Technology, 10044 Stockholm, Sweden

3 Department of Materials Science and Engineering, The Ohio State University, Columbus, $\mathrm{OH} 43210$

4 Materials Measurement Science Division, National Institute of Standards and Technology, 100 Bureau Dr., Gaithersburg, MD 20899 experimental composition profiles from the diffusion couples. Both experimental data and previous diffusion mobility descriptions in the literature for the bcc Ti-Al-V phase are adopted. A complete description of diffusion in both the hcp and bcc phases for the Ti-Al-V system is presented with the aim to be used for design of Ti alloys and processes.

Keywords CALPHAD · diffusion couples · diffusion modeling $\cdot$ interdiffusion $\cdot \mathrm{Ti}-\mathrm{Al}-\mathrm{V}$

\section{Introduction}

A large portion of the Ti grades are comprised of a microstructure that contains the $\alpha$-phase (hcp, hexagonal close-packed). Examples are the $\alpha$-grades (e.g. Ti-5Al-2Sn$3 \mathrm{Li}$ and Ti-8Al-1Mo-1V), the near- $\alpha$ grades (e.g., Ti-6Al2Sn-4Zr-2Mo and Ti-5Al-5Sn-2Zr-2Mo) and the duplex $\alpha+\beta$ grades (e.g., Ti-6Al-4V). Despite the commonly occurring $\alpha$ and near- $\alpha$ alloys, surprisingly limited research has concerned diffusion of typical alloying elements in the $\alpha$-phase. Only one measurement of the interdiffusion coefficient for the $\alpha$-phase in the Ti-Al system is available $^{[1]}$ and, to our knowledge, there is no published experimental diffusion data for the diffusion in the $\alpha$-phase of the Ti-V system. The lack of data for diffusion in $\alpha-\mathrm{Ti}$ systems is associated with challenges doing low-temperature diffusion experiments ( $\alpha$ is stable below about $1160 \mathrm{~K}$ for pure $\mathrm{Ti}$ ) and low solubilities of many alloying elements in the $\alpha$-Ti matrix. For example, the maximal solubility of $V$ in $\alpha-T i$ is $0.0385 \mathrm{~mol}$ fraction $^{[2,3]}$ and is located at $830 \mathrm{~K}$ which makes design of diffusion experiments challenging. Another major challenge with diffusion in the $\alpha$-Ti systems is the physical characteristics of the phase itself. Firstly, $\alpha$ 
Table 1 Compositions for the diffusion couple end-members in mole fraction measured by EDS

\begin{tabular}{lllll}
\hline End-members & \multicolumn{3}{c}{ Compositions (mole fraction) } & \multicolumn{1}{c}{ Homogenization } \\
\cline { 2 - 5 } & \multicolumn{2}{c}{$\mathrm{Al}$} & $\mathrm{V}$ & $\mathrm{TI}$ \\
\hline $\mathrm{A}$ & $\ldots$ & $\ldots$ & 1.00 & $24 \mathrm{~h}$ at $1473 \mathrm{~K}+120 \mathrm{~h} \mathrm{at} 923 \mathrm{~K}$ \\
$\mathrm{~B}$ & $\ldots$ & $0.015 \pm 0.001 / 0.018 \pm 0.001$ & Balance & $240 \mathrm{~h}$ at $923 \mathrm{~K}$ \\
$\mathrm{C}$ & $0.044 \pm 0.001$ & $0.024 \pm 0.001$ & Balance & $240 \mathrm{~h}$ at $923 \mathrm{~K}$ \\
$\mathrm{D}$ & $0.120 \pm 0.001$ & $\ldots$ & Balance & $24 \mathrm{~h}$ at $1473 \mathrm{~K}+120 \mathrm{~h}$ at $923 \mathrm{~K}$ \\
$\mathrm{E}$ & $0.057 \pm 0.001$ & $\ldots$ & Balance & $24 \mathrm{~h}$ at $1473 \mathrm{~K}+120 \mathrm{~h}$ at $923 \mathrm{~K}$ \\
\hline
\end{tabular}

All samples were homogenized before they were combined into diffusion couples and exposed to the interdiffusion heat treatments

is hexagonal structure and hence, anisotropy in the diffusion behavior is expected. Secondly, $\alpha$-Ti belongs to the group of matrix elements for which abnormally fast diffusion of solutes has been observed ${ }^{[4]}$ and several reasons for this have been proposed. ${ }^{[5-8]}$ The diffusion coefficient values have also been shown to be sensitive to the amount of impurities present, particularly Fe. ${ }^{[9]}$ For example, the measurement of the Ti self-diffusion in ultra-pure $\alpha$-Ti $(<0.000003$ mass fraction impurities $)$ show a diffusion rate normal for an $\alpha$ structure and the diffusion can be concluded to proceed via the vacancy-mechanism. ${ }^{[10]}$ When impurities are present, even in very low amounts, self-diffusion coefficients for $\alpha$-Ti have been measured to orders of magnitudes larger. The situation is the same for diffusion of solutes in $\alpha$-Ti such as $\mathrm{Al}$ diffusion in $\alpha-\mathrm{Ti}^{\left[{ }^{[9]}\right.}$ and could also be the case for $V$ diffusion in $\alpha$-Ti although this has not been confirmed experimentally. That the presence of extremely low impurity contents has a noticeable effect on the diffusion in $\alpha$-Ti is important to keep in mind when working with Ti alloys. One of the most common Ti minerals is ilmenite $\left(\mathrm{FeTiO}_{3}\right)$ and unless ultrapure $\mathrm{Ti}$ is used, the $\mathrm{Fe}$ impurity content will be at levels where it affects the diffusion; i.e., measurement on commercial Ti and all commercial Ti alloys will be influenced by impurities. Furthermore, small amounts of $\mathrm{O}$ are also known to influence the thermodynamics of the Ti systems notably. ${ }^{[3]}$

The current work aims to develop a CALPHAD (CALculation of PHAse Diagrams) description for the diffusion mobilities in the $\alpha$ and $\beta$ phases of the Ti-Al-V system. The CALPHAD method ${ }^{[11]}$ is an approach to describe phase-based properties for multicomponent, multiphase materials. The goal is to, for all the lower order systems (elemental, binary and ternary), describe a property of each phase relevant for the complete system in the form of parameterized functions. The parameters for these functions are assessed using pertinent input data. In the case of CALPHAD modeling of diffusion, the described property is the so-called atomic mobility which is the kinetic part of diffusion coefficients. To assess the mobility parameters for each phase, diffusion information is used, either obtained by experimental methods or calculated from first-principles. This can, for example, be diffusion coefficients or composition profiles from diffusion couple experiments.

Due to the sparse amount of information available for diffusion in the $\alpha$-Ti phase, the experimental work in this study is dedicated to filling information gaps for diffusion in the Ti-Al-V system. Only alloys of nominal purity are studied which means that the final results will incorporate impurity effects. From a modeling point of view, descriptions of pure $\mathrm{Ti}$ and its impurity effects would be ideal. However, for this work, the experimental capabilities to monitor impurities were not available. Nonetheless, the strength of the CALPHAD method is its ability to extrapolate into multicomponent compositional space and hence, its usefulness for realistic materials that are commercially used. Consequently, materials descriptions for impurityfree Ti systems for most applications would not be useful. In the next section the experimental procedure is described followed by the diffusion mobility models and the applied modeling strategies. Available diffusion data in the literature is reviewed in sections 4 and 5 , the experimental and the modeling results are presented and discussed. The final sections include information about raw data storage and sharing via the configurable data curation system (CDCS) being developed at the National Institute of Standards and Technology (NIST) and conclusions.

\section{Experimental Procedure}

To study diffusion in the Ti-Al-V system, diffusion couples were assembled using end-members with the nominal compositions listed in Table 1. A calculated isothermal section at $923 \mathrm{~K}$ is shown in Fig. 1. For the calculation, a thermodynamic description was developed based on previously published descriptions of the Ti-Al-V system ${ }^{[12,13]}$ and was adjusted to account for the recently published Ti-V description. ${ }^{[3]}$ The thermodynamic database is included in the Supplementary material of this publication. The end compositions were selected for the purpose of studying the 


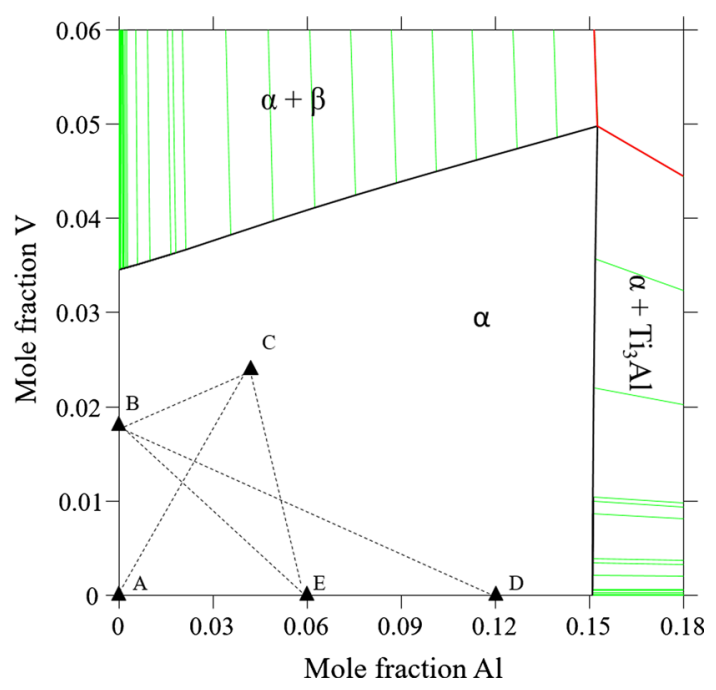

Fig. 1 Calculated Ti-Al-V isothermal section at $923 \mathrm{~K}$ showing the Ti-rich corner and the selected end-member compositions for the diffusion couples (A-E: symbols). The thermodynamic description applied is included in the Supplementary material and it is developed based on the Ti-Al- $\mathrm{V}^{[12,13]}$ description and previously published $\mathrm{Ti}$ $\mathrm{V}^{[3]}$ description

diffusion in the single-phase $\alpha$ region. The selected compositions enable investigation of the interdiffusion in the two Ti-containing binaries as well as three diffusion paths in the ternary system. In addition, at the composition of the cross-points for the diffusion paths, the ternary interdiffusion coefficients can be determined.

The end-member alloys were arc-melted from $\mathrm{Ti}, \mathrm{Al}$, and $\mathrm{V}$, with purities in mass fractions of $0.9999,0.99999$, and 0.999 , respectively. Homogenization is performed with the samples encapsulated ampules with lapping Ta films. The purpose of the homogenization treatment is to remove potential micro-segregation stemming from the solidification and to enlarge grains in order to reduce grain boundary diffusion effects. Homogenization times and temperatures are listed in Table 1. Due to the known influence of Fe and $\mathrm{O}$ impurities on the thermodynamic and diffusion characteristics of Ti systems, the $\mathrm{Fe}$ and $\mathrm{O}$ contents were measured for all samples after homogenization. It was concluded that the samples contain around (0.000150.00029) mass fraction $\mathrm{Fe}$ and around (0.0005-0.0007) mass fraction $\mathrm{O}$. It is worth noting that sample A showed the same order of $\mathrm{O}$ content compared to the as-received $\mathrm{Ti}$ used to make the end-members, which implies that there was no uptake of $\mathrm{O}$ during arc-melting and homogenization.

The treated ingots were cut into cylindrical pieces with a radius of $5 \mathrm{~mm}$ and thickness of $3 \mathrm{~mm}$. The contact surfaces of the pieces were ground and polished to a finish obtained with $1 \mu \mathrm{m}$ diamond suspension. The polished pieces were cleaned in ethanol and methanol as well as stored in $\mathrm{O}$ depleted de-ionized water (D/I water).
Mounting of columnar stacks of the various alloys (to obtain diffusion couples) was also performed in a bath of $D / I$ water in order to minimize formation of an oxide scale on the adjacent faces. For the interdiffusion heat treatment, a Mo-alloy (TZM) clamp was used to press the parts together. Tantalum foils were used at the ends of the stacks in order to prevent interdiffusion between the Mo alloy and the end-members.

Complete prevention of oxide scale formation at the surfaces is not practically possible and this work has only aimed at performing an identical sample preparation process and minimizing its thickness given the existing experimental facilities. However, the thickness of the oxide scales and potential $\mathrm{O}$ in-diffusion at the surfaces were compared for each samples to ensure that the conditions for the different end-member alloys are the same despite different compositions and being from different arc-melting batches. Thus, the oxide layer thickness was estimated using angle-resolved x-ray photoelectron spectroscopy (ARXPS), which provides information about film thickness and composition depth profiles. ARXPS was carried out on an Axis Ultra DLD XP spectrometer from Kratos Analytical (Chestnut Ridge, NY) ${ }^{1}$ to look at the attenuation of the titanium bulk signal as a function of the angle between the surface normal and the vector for the electron analyzer to collect photoelectrons. Specimens were mounted onto a stage individually and loaded into the vacuum chamber $\left(P_{\text {base }}=2 \times 10^{-9}\right.$ torr $)$. Photoemission was achieved using monochromatic $\mathrm{Al} \mathrm{K} \alpha$ x-rays located 60 degrees from the vector for the electron analyzer to collect photoelectrons. The stage was adjusted to roughly $0,15,30,40$ and 50 degrees in order to collect spectra at different angles. The Ti $2 p$ region was employed to monitor changes in the Ti[0] intensity and Ti[ox] intensity as a function of angle. Ti $2 p$ was fit with a set of peaks with a focus on correctly and consistently separating the Ti[0] intensity from all other Ti $2 p$ intensity, which we attributed generically to the Ti[ox] contributions, using CasaXPS (Teignmouth, UK). To obtain a value for the over layer thickness using ARXPS, the following equation was employed ${ }^{[14]}$ :

$I_{\theta}=I_{0} e^{-d /(\lambda \cos \theta)}$

where $I_{\theta}$ is the photoelectron intensity at a given angle, $I_{0}$ is the intensity of at 0 degrees, $d$ is the thickness of the sample, and $\lambda$ is the inelastic mean free path $(\lambda=2.17 \mathrm{~nm})$ of a $1030 \mathrm{eV}$ photoelectron travelling through $\mathrm{TiO}_{2}$. By plotting $\ln \left(I_{\theta} / I_{0}\right)$ versus $1 /(\cos \theta)$ and applying a linear fit,

\footnotetext{
${ }^{1}$ Certain commercial equipment, instruments, software or materials are identified in this paper to foster understanding. Such identification does not imply recommendation or endorsement by the Department of Commerce or the National Institute of Standards and Technology, nor does it imply that the materials or equipment identified are necessarily the best available for the purpose.
} 
one can extract a value for $-d / \lambda$. In order to separate the impact of the carbonaceous over layer, we repeated this process using the Ti[0] intensity for values of $I$ (this yields a thickness for the oxide $+\mathrm{C}$ over layer), as well as the Ti[ox] intensity (this yields a thickness for just the $\mathrm{C}$ over layer), thereby allowing us to calculate the thickness of the oxide layer by subtracting the two values.

Lastly, the thickness measurements were compared with some depth profiling measurements with a focus on thickness of oxygen contributions at the surface, or the depth of oxygen diffusion. Depth profiling was accomplished with $40 \mu \mathrm{A}$ argon ions accelerated to $2 \mathrm{kV}$ and rastered over a $4 \times 4 \mathrm{~mm}$ area of the surface. A $228 \mathrm{~nm}$ $\mathrm{SiO}_{2}$ control etched under the same conditions was employed as a calibrant for etch rate.

The diffusion couple combinations listed in Table 2 were heat treated at $923 \mathrm{~K}$ for $2400 \mathrm{~h}$, at $1023 \mathrm{~K}$ for $150 \mathrm{~h}$ and at $1123 \mathrm{~K}$ for $600 \mathrm{~h}$, respectively. After the diffusion treatment, the couples were mounted in epoxy, sectioned parallel to the columnar direction, ground and polished. All diffusion couples were examined by Scanning Electron Microscopy (SEM) for quality of the bond regions. Composition profiles were measured using a JEOL JSM-7100 FE-SEM with an Oxford Instruments X- Max ${ }^{\mathrm{n}} 80$ silicon drift detector (SDD). The FE-SEM conditions were $15 \mathrm{keV}$ and $0.5 \mathrm{nA}$. The acquisition times were chosen as $1000 \mathrm{~s}$ for elemental standards and $250 \mathrm{~s}$ for samples. The NIST developed free software, desktop spectrum analyzer (DTSA) $\mathrm{II}^{[15]}$ was used for quantifying the Energy Dispersive Spectroscopy (EDS) data. This software utilizes multiple linear least squares (MLLS) to solve for the unique proportional combination of spectra from standards to recreate the spectra from an unknown. Previously, peaks in the energy spectrum from different elements that overlap were too difficult for EDS to quantify accurately. Transition metals in particular were problematic as the $\mathrm{K} \beta$ spectral peak from one element overlaps the $\mathrm{K} \alpha$ from the following element in the periodic table. This is the case for Ti and V. However, this problem is overcome using the MLLS fitting in DTSA II in addition to higher count rates in the EDS analysis and good stability of the modern SDDs. ${ }^{[15,16]}$

The concentration profiles of each diffusion couple were measured along 3-5 parallel lines using the point analysis mode across the diffusion zone with steps of $1 \mu \mathrm{m}$. The
DTSA II software provided the estimated standard deviation of the composition measurements in mass fraction, which was converted to mole fraction.

Data smoothing was performed for each of the measured composition profiles following the procedure described by Moon et al. ${ }^{[17]}$ and resulted in splined composition functions. The splined data was used to compute the Matano interface positions and by positioning the Matano position at the same value for all composition profiles, the composition profiles for each diffusion couple were merged into one data set. The merged data sets were used as input for the diffusion mobility modeling as described in the following section.

\section{Diffusion Mobility Modeling}

Assuming the vacancy exchange mechanism for diffusion in a crystalline phase, the diffusion coefficient defined in the lattice-fixed frame of reference, $D_{k j}^{L}$, can be expressed as a product of an atomic mobility term and a thermodynamic term; i.e. the thermodynamic factor. If further, the molar volumes are assumed to be constant, the diffusivities in Eq 2 can be re-written to a volume-fixed frame of reference, $D_{k j}^{V}$,

$D_{k j}^{L}=\sum_{i=1}^{n} M_{k i}^{L} \frac{\partial \mu_{i}}{\partial x_{j}}$

and

$D_{k j}^{V}=\sum_{i=1}^{n}\left(\delta_{i k}-x_{k}\right) x_{i} M_{i} \frac{\partial \mu_{i}}{\partial x_{j}}$

Here, the species denoted $j$ is the diffusing species and $k$ is the gradient specie. $\mu$ is the chemical potential, $x$ is the mole fraction of the elements and $\delta$ is the Kröncker-delta. The thermodynamic factor, $\partial \mu_{i} / \partial x_{j}$, can be calculated easily using an appropriate multicomponent thermodynamic data description. The atomic mobility matrix, $M_{k i}^{L}$, can be both composition and temperature dependent and defines the diffusion mobilities in the lattice-fixed frame of reference. The composition dependency can be modeled following the CALHAD approach as developed by Andersson and Agren. ${ }^{[18]}$ Here, the off-diagonal terms of
Table 2 Diffusion couple combinations (marked boxes) and analyzed interdiffusioneor heat treatment temperatures and times

\begin{tabular}{lccc}
\hline Combinations & $2400 \mathrm{~h}$ at $923 \mathrm{~K}$ & $150 \mathrm{~h}$ at $1023 \mathrm{~K}$ & $600 \mathrm{~h}$ at $1123 \mathrm{~K}$ \\
\hline $\mathrm{A}-\mathrm{B}$ & $\mathbf{\square}$ & $\mathbf{\square}$ & \\
$\mathrm{B}-\mathrm{D}$ & $\mathbf{\square}$ & $\mathbf{\square}$ & \\
$\mathrm{B}-\mathrm{E}$ & & $\mathbf{\square}$ & \\
$\mathrm{A}-\mathrm{C}$ & $\mathbf{\square}$ & & \\
$\mathrm{C}-\mathrm{E}$ & & \\
\hline
\end{tabular}


the diffusion mobility matrix are assumed to be zero; i.e., correlation effects are either negligible or incorporated in the interaction terms of the diagonal elements. The diagonal terms of the mobility matrix are defined as

$M_{k i}^{L}=\delta_{k i} x_{i} M_{i}$

$M_{i}=M_{0} \frac{1}{R T} \exp \left(\frac{-\Delta Q_{i}^{*}}{R T}\right)$,

where $M_{i}$ is the mobility of a species, $i$, in a specific phase. Hence, the mobility can be described as the product of one jump frequency term, $M_{0}\left(\mathrm{~m}^{2} / \mathrm{s}\right)$, and a term dependent on the diffusion activation energy, $\Delta Q,(\mathrm{~J} / \mathrm{mole})$. It is the $\Delta Q$ and $R T \cdot \ln \left(M_{0}\right)$ that are modeled for each phase and stored in a CALPHAD diffusion mobility database. Ågren et al. ${ }^{[18-23]}$ expressed the composition dependence of these terms using a Redlich-Kister polynomial, ${ }^{[24]}$

$\Delta Q_{i}^{*}=\sum_{j} x_{j} Q_{i}^{j}+\sum_{p} \sum_{j>p} x_{p} x_{j} \sum_{k} A_{i}^{p j}\left(x_{p}-x_{j}\right)^{k}$.

The $Q_{i}^{j}$ represents the so-called end-members and the $A_{i}^{p j}$ is the interaction. A benefit with the CALPHAD approach is the relative small number of parameters that need to be stored when mobilities are modeled and stored instead of diffusion coefficients. Another strength is the ability to extrapolate into multicomponent space once the lower-order sub-systems have been assessed. The challenge with this method is that functions need to be assessed for all end-members since this also includes nonstable fictive end-members such as mobilities in the $\alpha-V$ (hcp) phase. To determine these types of end-members, empirical relations are used to correlate diffusion activation energies for a given crystal structure to the melting temperature $^{[25]}$ and self- and impurity diffusion coefficients. ${ }^{[26]}$

To assess expressions for the CALPHAD mobility descriptions, both diffusion coefficients and composition profiles from diffusion couple experiments are used as direct input. ${ }^{[27]}$ There are different types of diffusion coefficients; the tracer diffusion coefficient which is independent of the thermodynamics

$D_{i}^{*}=R T M_{i}$.

where $R$ is the gas constant, and the chemical diffusion coefficients which consist of the mobility part and the thermodynamic factor, see Eq 3. The tracer diffusion coefficients are preferred for diffusion mobility assessments as they are independent of the thermodynamic description. However, chemical diffusion coefficients such as the interdiffusion coefficients,

$\tilde{D}_{k j}^{n}=D_{k j}^{V}-D_{k n}^{V}$,

are the most commonly reported diffusion data. This makes the assessments dependent on what thermodynamic data that was used to calculate the thermodynamic factors. Consequently, a published diffusion mobility description should always be accompanied by a thermodynamic description. For this reason, the thermodynamic database for the Ti-Al-V system applied in the current work is included in the Supplementary material of this publication. The database is developed based on published Ti-V and TiAl-V descriptions. ${ }^{[3,12,13]}$

\section{Diffusion Coefficients}

\subsection{Determination of Diffusion Coefficients from Experimental Data}

Diffusion coefficients are often measured using indirect methods; a model is needed to relate the measured quantity to the diffusion coefficient. The resulting coefficients will hence depend both on the accuracy of the experimental diffusion data as well as assumptions of the models used. To compute chemical interdiffusion coefficients, the Matano-Boltzmann method ${ }^{[28,29]}$ is commonly used as well as the Sauer-Freise method. ${ }^{[30]}$ The latter is preferred as it does not depend on the Matano interface position and hence, inaccuracy associated with the Matano positions will not introduce additional errors in the diffusion coefficients. However, there is uncertainty associated with determining the composition profiles at the two ends of a diffusion couples profile when the noise in the EDS measurements is on the same order of magnitude as the dilute compositions. This makes both the Matano-Boltzman and the Sauer-Freise methods incapable of accurately evaluating impurity diffusion coefficients. Hall ${ }^{[31]}$ developed a method to extract impurity diffusion coefficients from regular diffusion couple composition profiles by assuming that the interdiffusion coefficients near the ends of the diffusion couple are constant. This method works for systems where diffusion coefficients are not strongly composition-dependent. However, the results of the Hall method are dependent on the choice of composition range for which the coefficients are constant and hence, it is difficult to decide which set of interdiffusion or impurity diffusion coefficients is the correct one. To overcome these difficulties, a forward-simulation analysis was developed by Zhang and Zhao ${ }^{[32]}$ which reliably evaluates both interdiffusion and impurity diffusion coefficients from diffusion couple composition profiles. ${ }^{[33]}$ The method uses the Sauer-Freise analysis to evaluate initial diffusion coefficient values which are used to define a function relating the diffusion coefficients to composition with adjustable parameters and then to simulate the interdiffusion in the diffusion couple. The calculated profile is compared with the measured profile and the diffusion coefficients are 
altered and reused in the simulation until the total summation of the least square errors is minimized. A similar approach has been used by Boettinger et al. ${ }^{[34]}$ when evaluating uncertainties associated with diffusion coefficient evaluations in the Ni-Re system.

Usually, diffusion coefficients are used as the input data when assessing diffusion mobilities for CALPHAD mobility descriptions. Another approach is to use diffusion couple composition profiles directly as input in a similar manner as described for the forward-simulation analysis. Instead of assessing values for the diffusion coefficients, it is the mobility parameters that are varied until minimum least square error summation is reached for the comparison of the simulated curve and the measured. Hence, this is an efficient method when the aim of the diffusion couple information is to build a CALPHAD diffusion mobility database. This assessment approach has been demonstrated by Campbell et al. ${ }^{[27]}$ and was used for the development of the NIST Ni superalloy mobility database. ${ }^{[35]}$ In the current work, start values of the impurity diffusion and binary interdiffusion coefficients for $\mathrm{Al}$ and $V$ diffusion in $\alpha$-Ti were evaluated using the forward-simulation analysis. ${ }^{[32]}$ These diffusion coefficients were then used as initial values for the diffusion mobilities. Final end-member values and mobility interaction parameters were then assessed using the diffusion couple composition profiles directly following the methods of Campbell et al. ${ }^{[27]}$ Codes for this method is available within the DICTRA software. ${ }^{[36]}$

\subsection{Diffusion Data for the Ti-Al-V System in the Literature}

Experimental literature information for diffusion in the Tirich $\alpha$-phase of the Ti-Al-V system is sparse. However, data for Ti self-diffusion is abundant although the purity of the Ti samples have a non-negligible influence as discussed in the Introduction. Work performed on ultra-pure $\mathrm{Ti}$ samples include the measurements by Köppers et al. ${ }^{[10,37]}$ Published relations for the Ti diffusion in $\alpha$-Ti which were obtained by experiment on less pure Ti alloys show a faster diffusion with a smaller activation energy, see for example the relation suggested by Räisänen et al ${ }^{[38]}$ and earlier work by Herzig et al. ${ }^{[39]}$ Köppers et al. ${ }^{[10,37]}$ also compared measurements of Ti self-diffusion and impurity diffusion of $\mathrm{Al}$ in $\alpha$-Ti in samples of different impurity levels. They concluded that both the self-diffusion and Al impurity diffusion in $\alpha$-Ti showed similar behavior with respect to the impurity level; i.e., in the high-purity sample the diffusion showed normal intrinsic behavior dominated by the vacancy mechanism and when impurities were present, the diffusion rate was strongly increased. Further measurements of $\mathrm{Al}$ diffusion in $\alpha$-Ti were performed by Araujo and Behar. ${ }^{[0]}$ Their results showed the same trend as
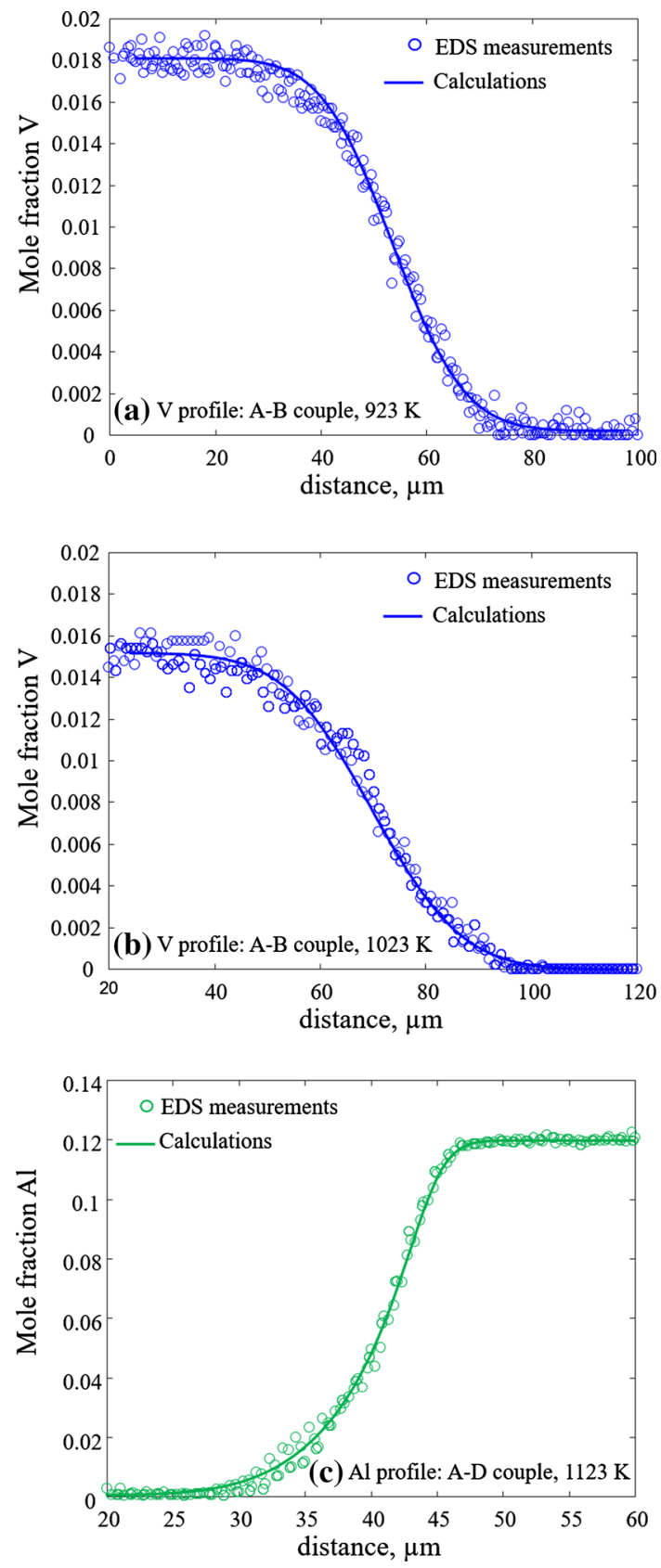

Fig. 2 Measured and calculated binary diffusion paths for Ti-V (AB) at $923 \mathrm{~K} \mathrm{(c)} \mathrm{and} \mathrm{at} 1023 \mathrm{~K}$ (b). Measured and calculated binary diffusion path for Ti-Al (A-D) at $1123 \mathrm{~K}(\mathrm{c})$. The standard deviation of the measured data points is typically $0.0005 \mathrm{~mol}$ fraction or lower

Köpper et al. ${ }^{[10,37]}$ but the coefficients were somewhat larger. The reason for the disagreement was not discussed by the authors. The same type of ultra-pure Ti samples were used by both group and hence, the purity cannot be the explanation. In addition to experimental data, a number of publications have reported diffusion coefficients calculated from first-principles. This includes the impurity diffusion coefficient of $\mathrm{Al}$ and $V$ in $\alpha$-Ti and the Ti selfdiffusion coefficient. ${ }^{[8,41,42]}$ 

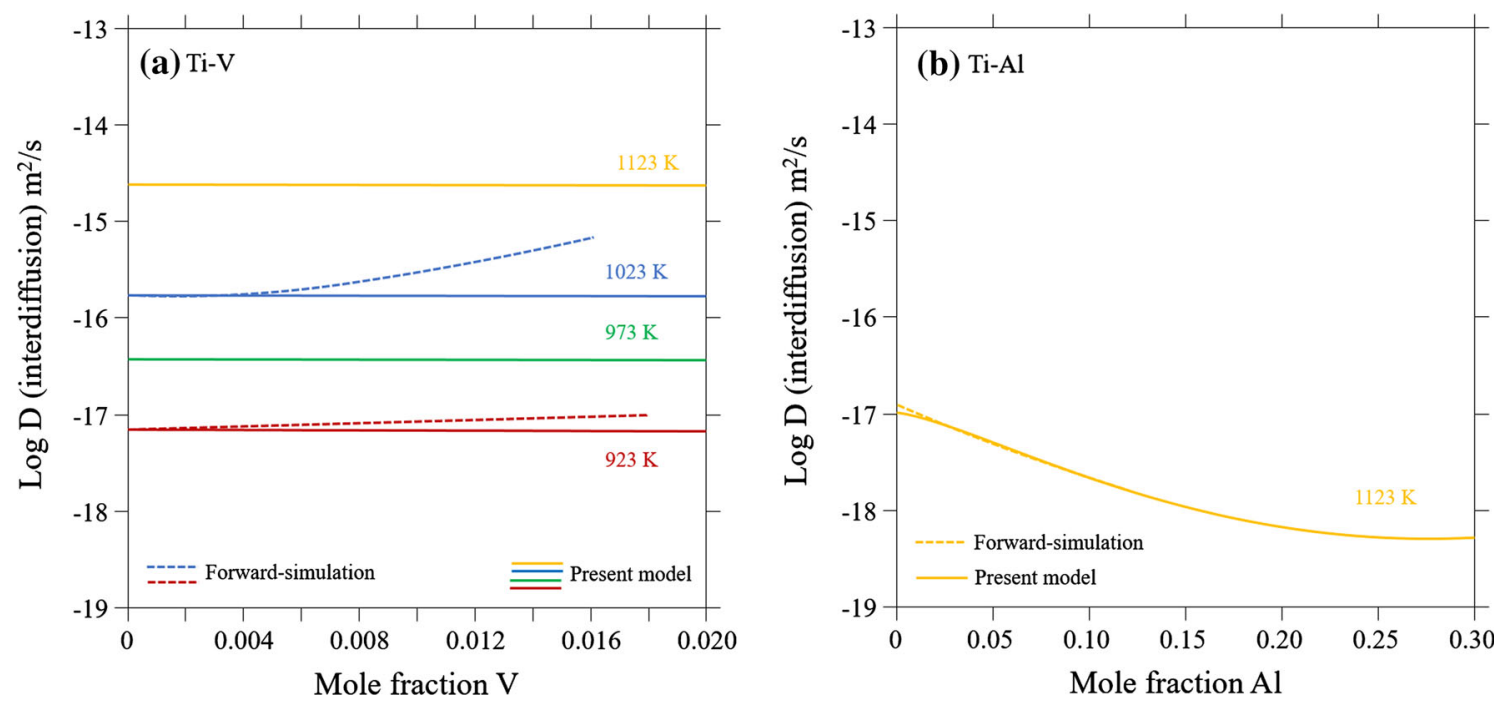

Fig. 3 Interdiffusion coefficients for the Ti-V system (a) and the Ti-Al system (b) evaluated using the forward-simulations (dashed lines) in comparison to the calculated coefficient using the final mobility descritpion (solid lines)
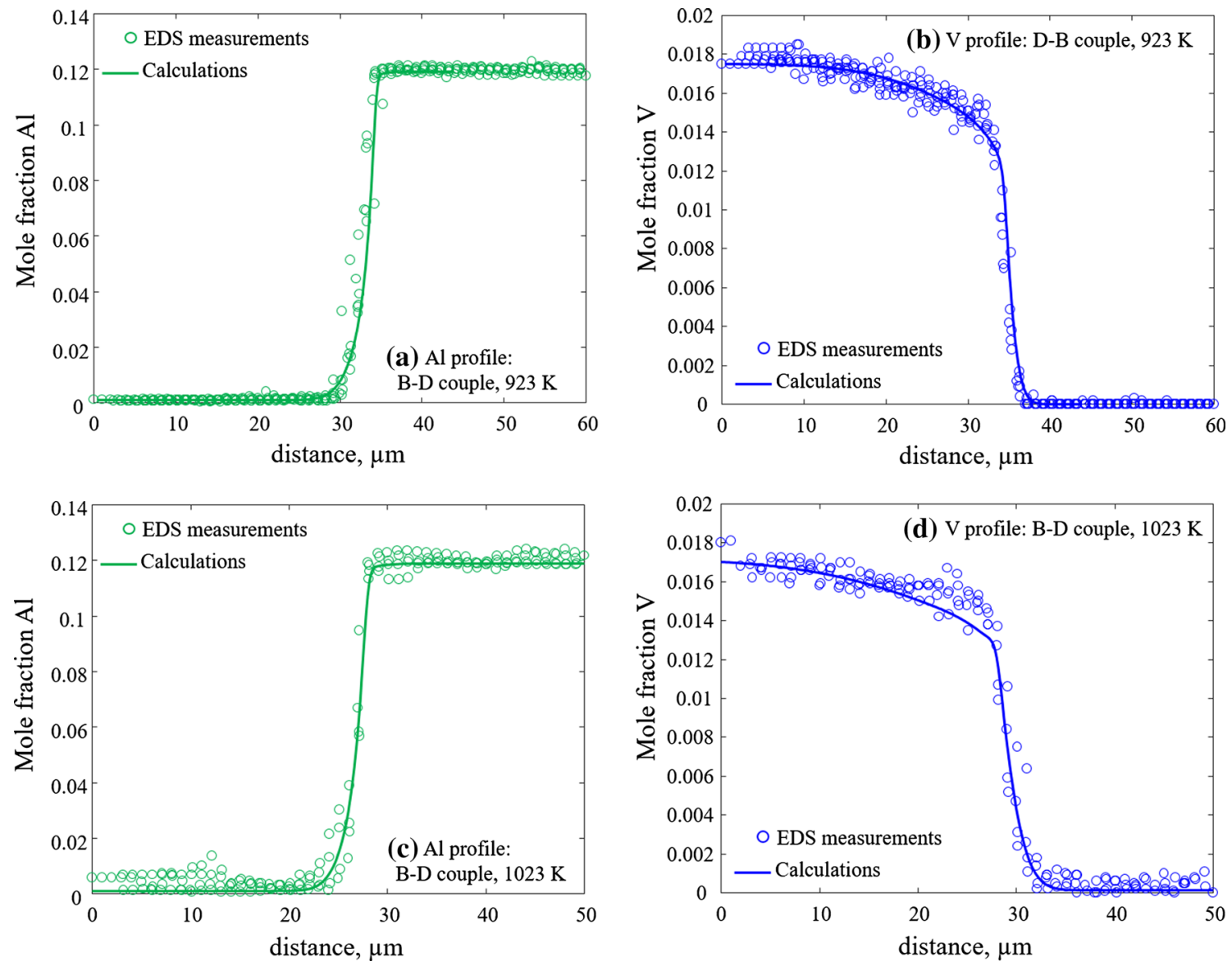

Fig. 4 Measured (symbols) and calculated (solid lines) $\mathrm{Al}$ and $V$ composition profiles for diffusion couple B-D at $923 \mathrm{~K}$ ((a) and (b)) and at $1023 \mathrm{~K}((\mathrm{c})$ and $(\mathrm{d}))$ 

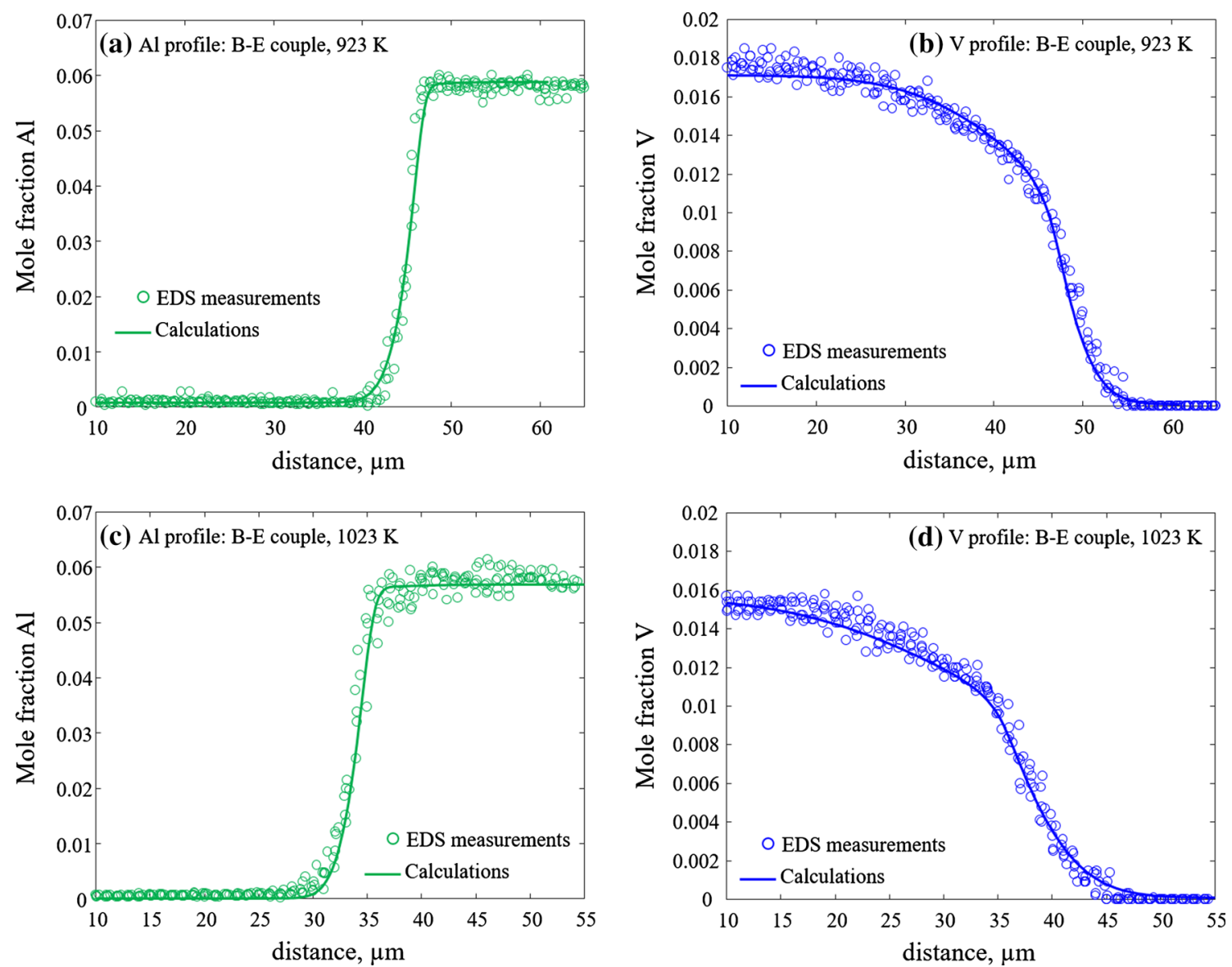

Fig. 5 Measured (symbols) and calculated (solid lines) $\mathrm{Al}$ and $V$ composition profiles for diffusion couple B-E at $923 \mathrm{~K}$ ((a) and (b)) and at $1023 \mathrm{~K}((\mathrm{c})$ and $(\mathrm{d}))$

In the case of diffusion in the Ti-rich $\beta$-phase of the TiAl-V system, several experimental datasets are available. Huang et al. ${ }^{[43]}$ reviewed experimental data for interdiffusion in the Al-Ti system published before the year 2011. This includes diffusion couple experiments by Goold, ${ }^{[44]}$ Gerold and Herzig, ${ }^{[45]}$ Ouchi et al., ${ }^{[1]}$ Araki et al. ${ }^{[46]}$ and Kainuma and Inden. ${ }^{[47]}$

Tracer diffusion studies have also been conducted for the Ti-Al system (for $\mathrm{Ti}_{90} \mathrm{Al}_{10}$ and $\mathrm{Ti}_{70} \mathrm{Al}_{30} \beta$ alloys). ${ }^{[45]}$ The result showed that the Arrhenius plots of the Ti tracer diffusion were anomalously curved for both alloys and exhibited negligible concentration dependence (within experimental uncertainty). For $\mathrm{Al}$ tracer diffusion in $\beta$-Ti, there is no data due to the low activity of ${ }^{26} \mathrm{Al}$ and the difficulty of $\mathrm{Al}$ coating pure Ti surfaces.

The work by Huang et al. ${ }^{[43]}$ included a CALPHAD diffusion mobility assessment of the $\beta$-phase and it was concluded that the best results were obtained by prioritizing the data by Ouchi et al., ${ }^{[1]}$ Gerold and Herzig ${ }^{[45]}$ and Araki et al. ${ }^{[46]}$ which all showed comparable results over the whole temperature range. The data by Goold ${ }^{[44]}$ is in contradiction to the others and was excluded. The reason for the contradiction seems to be poor purity of raw materials. The Ti-Al binary description by Huang et al. ${ }^{[43]}$ was adapted by $\mathrm{Li}$ et al. ${ }^{[48]}$ when modeling the $\mathrm{Ti}-\mathrm{Al}-\mathrm{Cr}$ system with a slight modification to fit their thermodynamic description of the ternary. A more recent assessment of the $\beta$ Ti-Al system was conducted by Chen et al. ${ }^{[49,50]}$ when assessing the Al-Ti-Fe and Al-Ti-Mo systems.

Vanadium self-diffusion in $\beta$-phase have been studied by several groups using either radioactive isotopes ${ }^{[51-56]}$ or nuclear magnetic resonance. ${ }^{[57,58]}$ Diffusion measurements for the binary Ti-V system were performed by Murdock et al. ${ }^{[59]}$ and by Murdock and McHargue. ${ }^{[60]}$ The latter also included a measurement of the tracer diffusion of $V$ in $\beta(\mathrm{Ti}, \mathrm{V})$. Chemical interdiffusion experiment for diffusion in $\beta \mathrm{Ti}-\mathrm{V}$ were also performed by Ugaste and Zakykin, ${ }^{[61]}$ Fedotov et al ${ }^{[62]}$ and Sprengel et al. ${ }^{[63]}$ Furthermore, the impurity diffusion coefficient for $V$ diffusion in $\beta$-Ti as well as interdiffusion coefficients in the Ti-V binary evaluated using the forward-simulation analysis were recently published by Zhu et al. ${ }^{[64]}$

Diffusion in the $\beta$-phase in the ternary Ti-Al-V system has been studied experimentally using diffusion couples. ${ }^{[65,66]}$ In addition to Huang et al.'s ternary CALPHAD mobility 

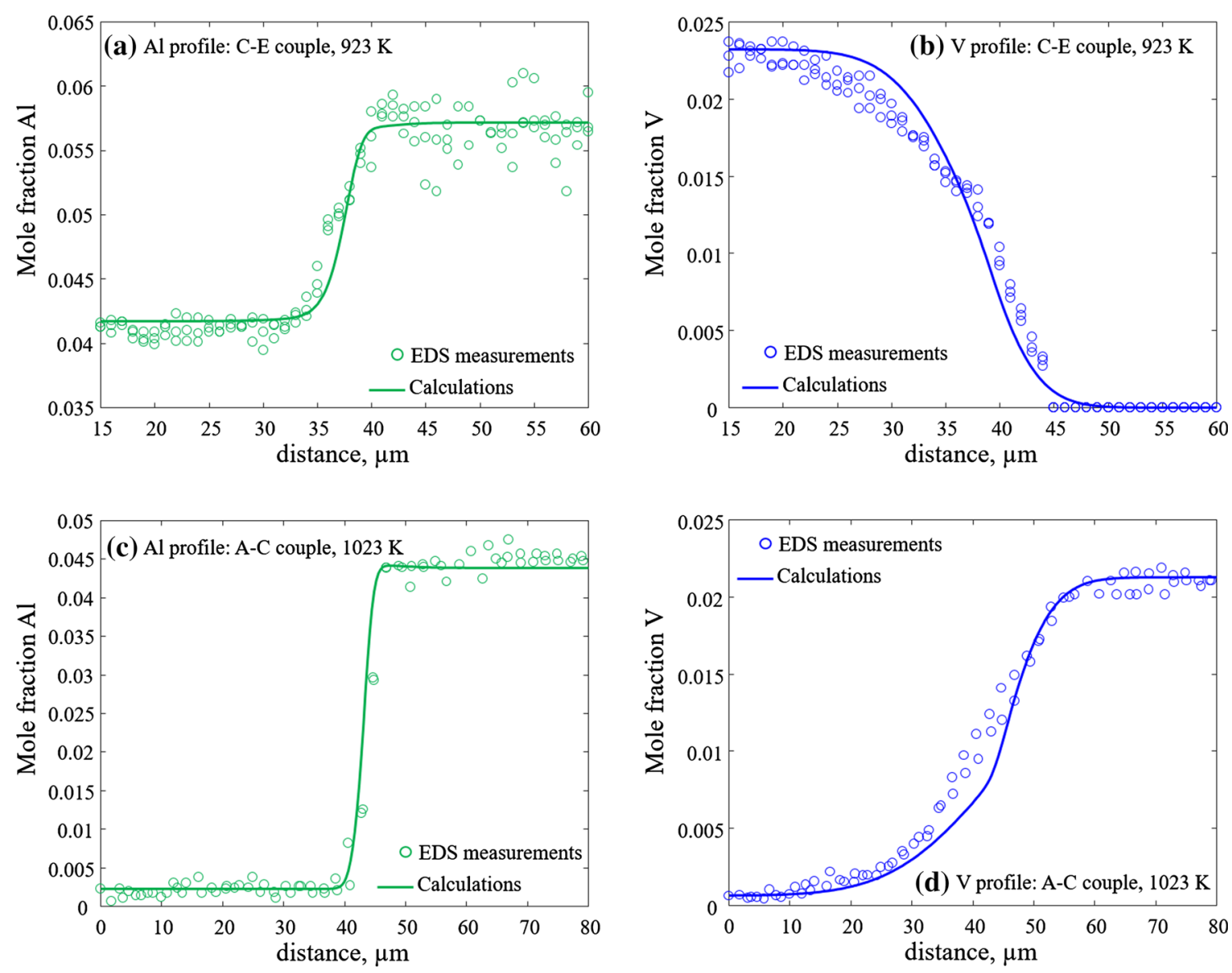

Fig. 6 Measured (symbols) and calculated (solid lines) $\mathrm{Al}$ and $V$ composition profiles for diffusion couple $\mathrm{C}$-E at $923 \mathrm{~K}$ ((a) and (b)) and for diffusion couple (A-C) at $1023 \mathrm{~K} \mathrm{((c)} \mathrm{and} \mathrm{(d))}$

description, ${ }^{[43]}$ Wang et al. $^{[67]}$ published a mobility description of the $\beta$ phase. Two different thermodynamic descriptions were used for the two assessments and hence, the resulting mobility parameters are quite different. Huang et al. used a thermodynamic description where the constituent binary systems are combined together and the ternary description was solely an extrapolation from these, whereas Wang et al. developed a ternary thermodynamic description for the $\beta$-phase in the Ti-Al-V system.

Finally, it should be mentioned that diffusion mobilities for both the $\alpha$ and the $\beta$ phase were performed by Chen et al. ${ }^{[68]}$ and used as input for phase field simulations. However, neither details of the assessment nor parameters were included in the publication.

\section{Results and Discussion}

\subsection{Experimental Results}

The measured diffusion composition profiles at $923 \mathrm{~K}$, $1023 \mathrm{~K}$ and $1123 \mathrm{~K}$ for the binary systems are shown in
Fig. 2(a), (b), and (c). The Al profiles for the binary diffusion couples (diffusion couple A-D) at $923 \mathrm{~K}$ and $1023 \mathrm{~K}$ were too steep to be used for the assessments and hence, an additional diffusion couple at $1123 \mathrm{~K}$ was conducted. At this temperature, $1123 \mathrm{~K}$, the $V$ containing samples are in the $\alpha / \beta$ two-phase region and therefore, only the Ti-Al system was analyzed in the currently work. The binary composition profiles were used as input for the diffusion mobility assessments described in the next section. Since measurements of the $V$ impurity diffusion coefficient were not previously available, the forwardsimulation analysis was used at both temperatures. Assuming an Arrhenius relation, the diffusion coefficients is $1.19 \times 10^{-3} \cdot \mathrm{e}^{-251470 / \mathrm{RT}} \mathrm{m}^{2} / \mathrm{s}$. The forward-simulation analysis gives the $\mathrm{Al}$ impurity diffusion coefficient $1.24 \times 10^{-17} \mathrm{~m}^{2} / \mathrm{s}$ at $1123 \mathrm{~K}$ which is higher than the diffusion coefficient measured for ultra-pure Ti samples. This is expected since the samples used for the current work are of nominal purity. The interdiffusion coefficient obtained from the forward-simulation is shown in Fig. 3 for the binary systems, Ti-V and Ti-Al. 

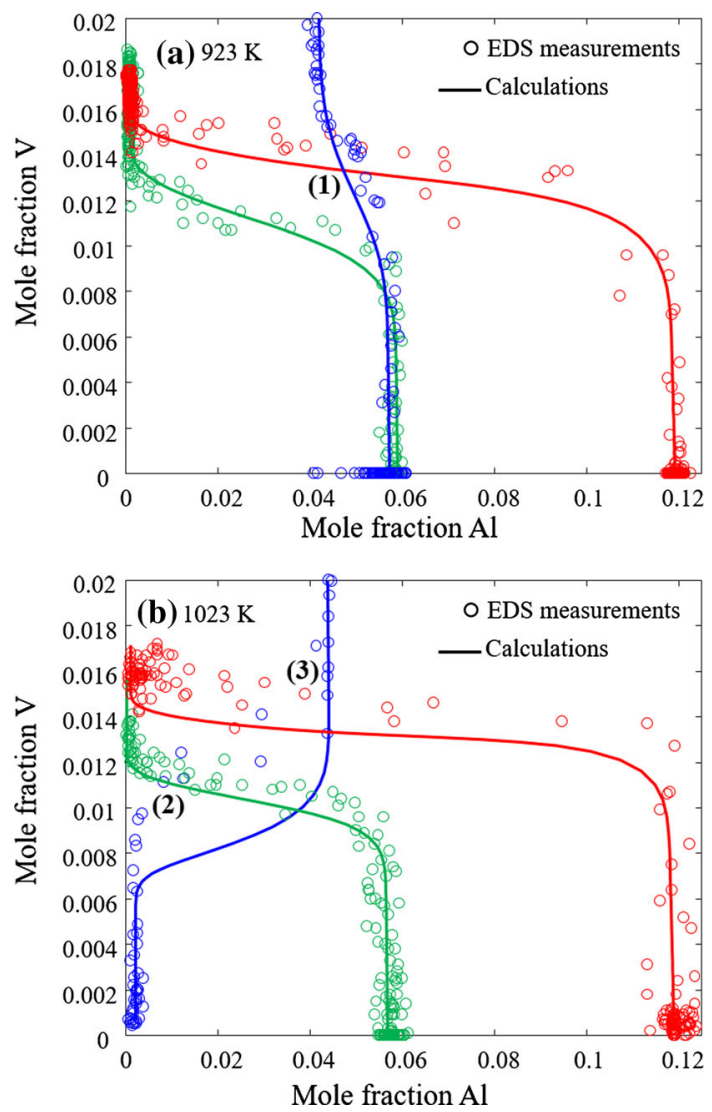

Fig. 7 Measured and calculated diffusion paths between composition $\mathrm{B}$ and $\mathrm{E}, \mathrm{B}$ and $\mathrm{D}$ and $\mathrm{C}$ and $\mathrm{E}$ at $923 \mathrm{~K}$ (a) and between composition $\mathrm{B}$ and $\mathrm{E}, \mathrm{B}$ and $\mathrm{D}$, and $\mathrm{A}$ and $\mathrm{C}$ at $1023 \mathrm{~K}$ (b). The standard deviation of the measured data points is typically $0.0005 \mathrm{~mol}$ fraction or lower. The numbers indicate the cross-point composition for which the ternary diffusion coefficients were calculated, see Table 4

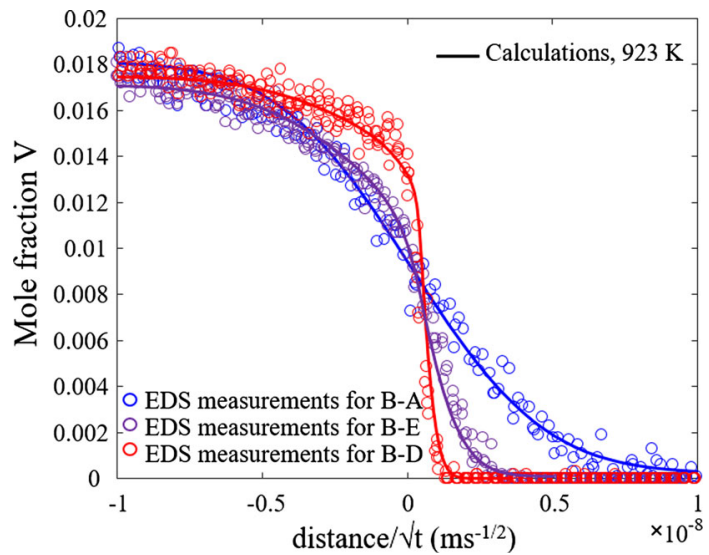

Fig. 8 Measured and calculated $V$ composition profiles between composition $\mathrm{B}$ and $\mathrm{A}, \mathrm{B}$ and $\mathrm{E}$, and $\mathrm{B}$ and $\mathrm{E}$ showing the influence of $\mathrm{Al}$ on the $V$ diffusion at $923 \mathrm{~K}$. The standard deviation of the measured data points is typically $0.0005 \mathrm{~mol}$ fraction or lower

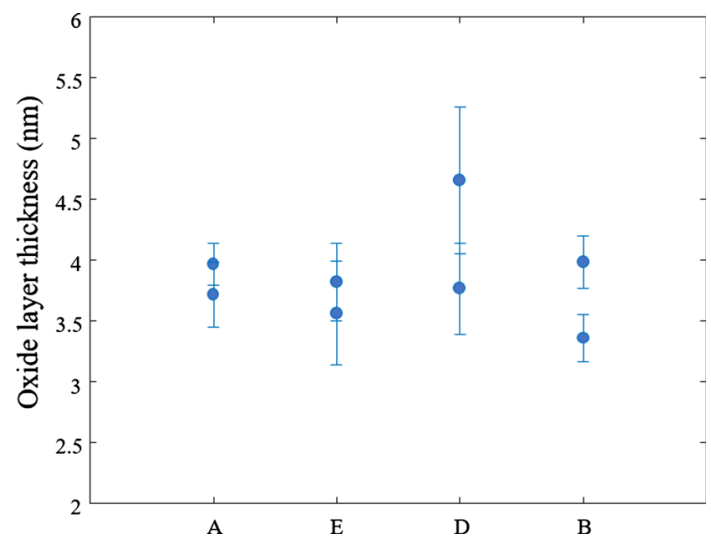

Fig. 9 Results of the ARXPS measurements showing the oxide scale thickness on the surface of sample A, E, D, and B

In Fig. 4, 5, 6, and 7 the measured composition profiles for the couples in the ternary system are shown as well as the measured ternary diffusion paths for the diffusion couples heat treated at $923 \mathrm{~K}$ and $1023 \mathrm{~K}$, respectively. This includes the composition profiles and diffusion paths between end-composition $\mathrm{B}$ and $\mathrm{D}, \mathrm{B}$ and $\mathrm{E}$ and $\mathrm{C}$ and $\mathrm{E}$ for the experiment at $923 \mathrm{~K}$, and between $\mathrm{B}$ and $\mathrm{D}, \mathrm{B}$ and $\mathrm{E}$ and $\mathrm{A}$ and $\mathrm{C}$ for the experiment at $1023 \mathrm{~K}$. In particular, the diffusion profile between $\mathrm{B}$ and $\mathrm{A}, \mathrm{B}$ and $\mathrm{E}$ and $\mathrm{B}$ and $\mathrm{D}$ are of interest to compare since they all consist of the binary Ti-V (B) side combined with alloys of different $\mathrm{Al}$ contents; i.e., $\mathrm{A}(0 \mathrm{Al}), \mathrm{E}(\sim 0.06 \mathrm{~mol}$ fraction $\mathrm{Al})$ and $\mathrm{D}$ $(\sim 0.12 \mathrm{~mol}$ fraction $\mathrm{Al})$. To visualize the interdiffusion behavior of $V$ in $\alpha$ Ti-Al with increasing $\mathrm{Al}$, the $V$ composition profiles for diffusion couple B-A, B-E and B-D at $923 \mathrm{~K}$ are shown together in Fig. 8. Figure 8 shows that the interdiffusion region becomes more narrow when $\mathrm{Al}$ is present in the $\alpha$ alloy; i.e., the experimental observations suggest that the $V$ diffusion in $\alpha$-Ti decreases with increasing $\mathrm{Al}$ content. The same trend is observed for the diffusion couples at $1023 \mathrm{~K}$.

To verify that the experimental observation is a compositional effect of $\mathrm{Al}$ on the $V$ diffusion, and not due to different conditions at the interfaces in contact for the different diffusion couples, the ARXPS measurements for sample A, D and E were compared. In Fig. 9, the measured thicknesses of the oxide scales for the three samples are shown. The error bar is large for this measurements since is it difficult to determine the exact position of the interface between the external oxide layer and the alloy. However, the three samples show similar oxide layer thicknesses; about (3.5-4) $\mathrm{nm}$. In addition, the $\mathrm{O}$ in-diffusion depth is similar for the three samples (A, D and E), about (4.7-8.6) $\mathrm{nm}$. This suggests that the experimentally observed effect of $\mathrm{Al}$ on the $V$ diffusion is a compositional effect and should be accounted for by the diffusion mobility description. 
Table 3 Assessed diffusion mobility parameters for the $\alpha$-phase in the Ti-Al-V ternary system

\begin{tabular}{|c|c|c|c|}
\hline DICTRA notation & Mobility parameter & Parameter & Reference \\
\hline MQ(HCP_A3\&Al,Al:VA;0) & $Q_{\mathrm{Al}}^{\mathrm{Al}}$ & $-79800+\mathrm{R} \cdot \mathrm{T} \cdot \ln \left(2.38 \times 10^{-5}\right)$ & 72 \\
\hline MQ(HCP_A3\&Ti,Al:VA;0) & $Q_{\mathrm{Ti}}^{\mathrm{Al}}$ & $-79800+\mathrm{R} \cdot \mathrm{T} \cdot \ln \left(2.38 \times 10^{-5}\right)$ & This work (assumption)(a) \\
\hline MQ(HCP_A3\&V,Al:VA;0) & $Q_{V}^{\mathrm{Al}}$ & $-79800+\mathrm{R} \cdot \mathrm{T} \cdot \ln \left(2.38 \times 10^{-5}\right)$ & This work (assumption)(a) \\
\hline MQ(HCP_A3\&Al,Ti:VA;0) & $Q_{\mathrm{Al}}^{\mathrm{Ti}}$ & $-193200+\mathrm{R} \cdot \mathrm{T} \cdot \ln \left(1.00 \times 10^{-8}\right)$ & This work \\
\hline MQ(HCP_A3\&Ti,Ti:VA;0) & $Q_{\mathrm{Ti}}^{\mathrm{Ti}}$ & $-303000+\mathrm{R} \cdot \mathrm{T} \cdot \ln \left(1.35 \times 10^{-3}\right)$ & This work \\
\hline MQ(HCP_A3\&V,Ti:VA;0) & $Q_{V}^{\mathrm{Ti}}$ & $-251490-56 \cdot \mathrm{T}$ & This work \\
\hline MQ(HCP_A3\&Al,V:VA;0) & $Q_{\mathrm{Al}}^{V}$ & $-258550+\mathrm{R} \cdot \mathrm{T} \cdot \ln \left(4.36 \times 10^{-2}\right)$ & This work (assumption)(c) \\
\hline MQ(HCP_A3\&Ti,V:VA;0) & $Q_{\mathrm{Ti}}^{V}$ & $-258550+\mathrm{R} \cdot \mathrm{T} \cdot \ln \left(4.36 \times 10^{-2}\right)$ & This work (assumption)(c) \\
\hline MQ(HCP_A3\&V,V:VA;0) & $Q_{V}^{V}$ & $-258550+\mathrm{R} \cdot \mathrm{T} \cdot \ln \left(4.36 \times 10^{-2}\right)$ & This work (estimation)(b) \\
\hline MQ(HCP_A3\&Al,Al,Ti:VA;0) & $A_{\mathrm{Al}}^{\mathrm{Al}, \mathrm{Ti}}$ & -491950 & This work \\
\hline MQ(HCP_A3\&Ti,Al,Ti:VA;0) & $A_{\mathrm{Ti}}^{\mathrm{Al}, \mathrm{Ti}}$ & -442800 & This work \\
\hline MQ(HCP_A3\&A1,Ti,V:VA;0) & $A_{\mathrm{Al}}^{\mathrm{Ti}, V}$ & +587700 & This work \\
\hline MQ(HCP_A3\&V,Ti,V:VA;0) & ${ }^{0} A_{V}^{\mathrm{Al}, \mathrm{Ti}}$ & -529600 & This work \\
\hline MQ(HCP_A3\&V,Al,Ti:VA;0) & ${ }^{1} A_{V}^{\mathrm{Al}, \mathrm{Ti}}$ & -130180 & This work \\
\hline
\end{tabular}

(a) Assumed to be the same as the $\alpha$-Al end-member published by Cui et al. ${ }^{[72]}$

(b) Estimated using the relation suggested by Askill ${ }^{[25]}$ with $T_{\mathrm{m}}=1413 \mathrm{~K}$ calculated using the SGTE description of $V^{[73]}$

(c) Assumed to be the same as the $\alpha-V$ end-member

\subsection{Diffusion Mobility Modeling}

The diffusion data for the $\alpha$ Ti-Al-V system generated in the current work was used for the mobility assessment along with selected literature data. The resulting model parameters are listed in Table 3. The calculated impurity diffusion coefficient for $\mathrm{Al}$ in $\alpha$-Ti is shown in Fig. 10(a) in comparison to experiment. The data by Räisänen et al. ${ }^{[38]}$ was used to obtain the temperature dependence of the impurity diffusion coefficient in the assessment. In the Fig. 10(a), the experimental datasets by Köppers et al., ${ }^{[10]}$ Araujo et al. ${ }^{[40]}$ and Räisänen et al. ${ }^{[38]}$ are also included. The measurements by Körpers et al. ${ }^{[10]}$ was performed on ultra-pure $\alpha$-Ti and hence, should be regarded as the most accurate dataset for the binary Ti-Al system. The measurement by Räisänen et al. ${ }^{[38]}$ resulted in larger diffusion coefficients and does not represent the binary Ti-Al system but the $\mathrm{Ti}-\mathrm{Al}+$ impurities system. Since the systems studied in the work include impurities and since the CALPHAD mobility description developed in this work is aimed to be applicable for commercial Ti alloys, our data together with the dataset by Räisänen et al. ${ }^{[38]}$ was adopted for the assessment in this work. The diffusion coefficient by Räisänen, is also close to the value obtained by the forward-simulation analysis.

In the case of $V$ impurity diffusion in $\alpha$-Ti, the current A-B diffusion couple results at $923 \mathrm{~K}$ and $1023 \mathrm{~K}$ were used as input and the results are shown in Fig. 10(b) in comparison to the impurity diffusion coefficient calculated from first-principles. ${ }^{[41]}$ The current model predicts faster diffusion of $V$ in $\alpha$-Ti compared to the calculations by $\mathrm{Xu}$ et al. ${ }^{[41]}$ The calculated diffusion coefficient is not expected to agree with the current experiment since the first-principles calculations were performed on an impurity- and defect free system whereas the current diffusion couple alloys are confirmed to contain impurities which enhance the diffusion. In addition, the first-principles value for the self-diffusion coefficient for $\alpha$-Ti is smaller than experimental literature data which indicates that the calculations are underestimating the values.

The calculated composition profiles and diffusion paths are shown in comparison with experimental data in Fig. 2, 4, 5, 6, and 7. To simulate interdiffusion, the diffusion software DICTRA was used. The profile optimization module within DICTRA was also used to assess the final values of the interaction parameters listed in Table 3. Acceptable agreement with experiments are confirmed for all composition profiles except for the profiles between composition $\mathrm{A}$ and $\mathrm{C}$ as well as between $\mathrm{C}$ and $\mathrm{E}$ (Fig. 6). The reason for this is currently not clear and ideally, more information about the composition interval for this diffusion path should be produced. However, in the current work, this discrepancy is accepted since good overall agreement was obtained for all the other diffusion paths in the system and since this overall agreement decreased when the A-C and C-E composition profiles were prioritized in the optimization. 

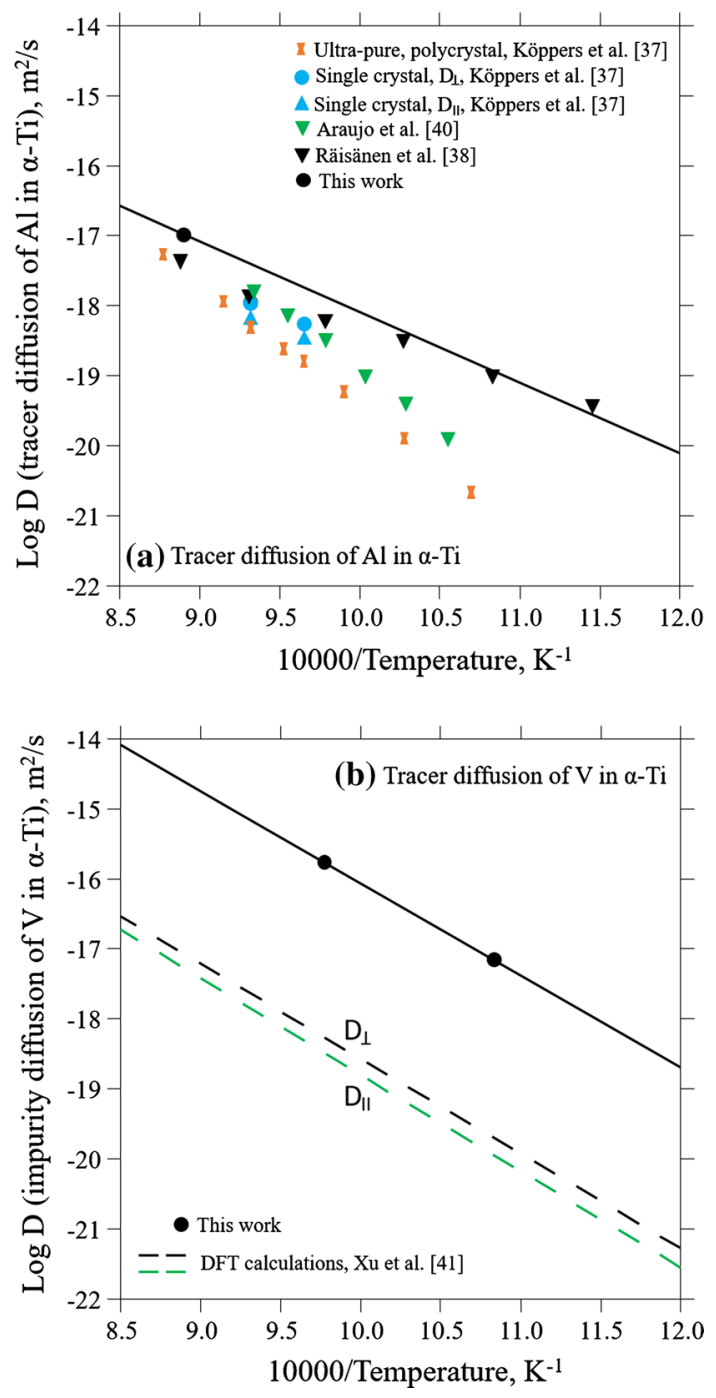

Fig. 10 Calculated diffusion coefficients (solid lines) in comparison to experimental ${ }^{[10,38,40]}$ and DFT data ${ }^{[41]}$ for $\mathrm{Al}$ impurity diffusion in $\mathrm{Ti}$ (a) and $V$ impurity diffusion in $\mathrm{Ti}$ (b)

Due to the poor agreement between the calculations and the measured A-C and C-E profiles, comparison of calculated ternary diffusion coefficients at the diffusion paths' cross-point compositions and the ternary diffusion coefficients determined from the measured profiles using methods within the ternary diffusion theory, is not expected to lead to good agreement. Nevertheless, for completeness, a comparison was still performed using the method suggested by Kirkaldy as described by Dayananda et al. ${ }^{[69]}$ The estimated ternary diffusion coefficients at $923 \mathrm{~K}$ for Ti containing $0.049 \mathrm{~mol}$ fraction $\mathrm{Al}$ and $0.014 \mathrm{~mol}$ fraction $V$ (1), and at $1023 \mathrm{~K}$ for Ti containing $0.012 \mathrm{~mol}$ fraction $\mathrm{Al}$ and $0.011 \mathrm{~mol}$ fraction $V(2)$ as well as $0.043 \mathrm{~mol}$ fraction $\mathrm{Al}$ and $0.014 \mathrm{~mol}$ fraction $V(3)$ are all listed in Table 4. At the same compositions, the ternary diffusion coefficient elements are calculated using the current mobility and thermodynamic descriptions, see Table 4 . For both temperatures, the estimated and calculated main diffusion coefficients, $D_{\mathrm{Al}, \mathrm{Al}}^{\mathrm{Ti}}$ and $D_{V, V}^{\mathrm{Ti}}$, are comparable whereas larger discrepancy is obtained for the off-diagonal matrix elements. The differences are due to several factors. For example, the cross-points of the diffusion paths are not located at the same composition for the simulated and measured diffusion paths which introduces uncertainties. This is an issue for composition (2) at $1023 \mathrm{~K}$ for which the simulated and measured cross-point compositions are notably different. Furthermore, the interdiffusion matrix elements are strongly dependent on the shape of the composition profiles. Hence, since it is apparent from Fig. 6 that the shape of the simulated $\mathrm{A}-\mathrm{C}$ and $\mathrm{E}-\mathrm{C}$ profiles and the measured profiles are different, discrepancies can be expected. In the current work, these discrepancies are accepted. These interdiffusion coefficients can be seen as an intermediate product and focus has instead been on finding the set of diffusion mobility parameters that, together with the full thermodynamic description of the system, best captures the observed diffusion behavior. As demonstrated in Fig. 8, the compositional effect of $\mathrm{Al}$ on the $V$ diffusion in the $\alpha$-phase is well reproduced by the developed mobility description. The consequences of this $\mathrm{Al}$ effect will be discussed further in next section.

The mobility description for the $\beta$-phase was adopted from the literature. ${ }^{[43]}$ Since a different thermodynamic description was used, which may affect the interdiffusion coefficients via the thermodynamic factor, the interdiffusion coefficients were calculated and compared with experiments. The comparisons with binary diffusion coefficients ${ }^{[1,45,61,62,64]}$ and ternary diffusion coefficients ${ }^{[70]}$ show acceptable agreement as illustrated in Fig. 11.

\subsection{Ternary Diffusion in the $\alpha$-Phase of the Ti-Al-V System}

Many Ti alloys contain $V$ contents above the $V$ solubility limit of the $\alpha$-phase. This is, for example, the case for the $\alpha+\beta$ alloy Ti-6Al-4V, which is one of the most important Ti alloys. If it is assumed that the $V$ content in a Ti-Al-V alloy is well above the $V$ solubility limit for the $\alpha$-phase, the phase will at all temperatures be saturated in V. As shown in Fig. 1, the $V$ solubility in $\alpha$-phase increases with increasing $\mathrm{Al}$ content; i.e., depending on the $\mathrm{Al}$ content of the alloy, the $V$ content in the $\alpha$-phase will vary. The results of the current work show that the $V$ diffusion is slowed down with increasing $\mathrm{Al}$ content, see Fig. 8. To quantify this in terms of diffusion coefficients, the main diffusion coefficient terms $\left(D_{V, V}^{\mathrm{Ti}}\right.$ and $\left.D_{\mathrm{Al}, \mathrm{Al}}^{\mathrm{Ti}}\right)$ at $923 \mathrm{~K}$ and $1023 \mathrm{~K}$ are plotted as a function of $\mathrm{Al}$ content in Fig. 12. For the calculation, the $V$ content is given by the solubility limit 


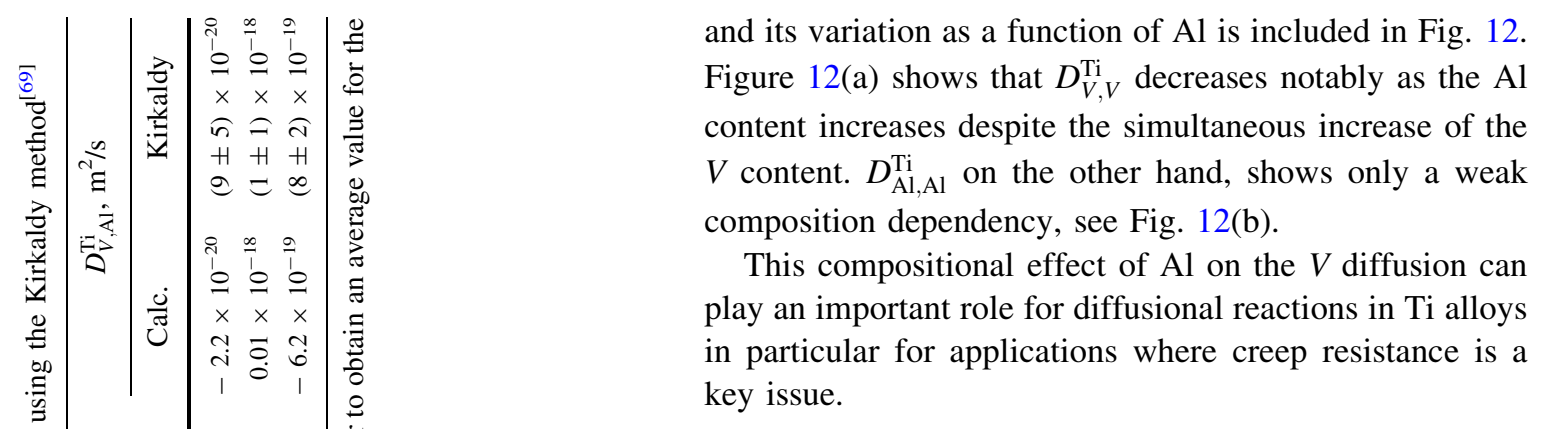

\subsection{Diffusion Data Collection}

The aim with the current work was to develop a CALPHAD diffusion mobility description that can be used for $\mathrm{Ti}$ alloy design and optimization of $\mathrm{Ti}$ alloy processing. The experimental data generated for this purpose may, however, be valuable for other applications. Furthermore, future work will increase the understanding of the diffusion behavior in the Ti-Al-V system and potentially more experimental as well as theoretical information of this system will be generated. It is therefore of interest to store the experimental data and metadata of this work in a searchable manner to enable curation and easy reuse. The $\mathrm{CDCS}^{[71]}$ is developed for this purpose and used in the current work. The data and metadata can be found at http:// phasedata.nist.gov.

\section{Conclusions}

Diffusion in the $\alpha$-phase of the Ti-Al-V system has, despite the importance of the phase, been sparsely studied in the past. In this work, diffusion couple experiments were therefore conducted to produce experimental data for diffusion in this phase. This included diffusion paths in the Ti-Al-V system at the temperatures $923 \mathrm{~K}, 1023 \mathrm{~K}$ and $1123 \mathrm{~K}$. A diffusion mobility description was developed using the CALPHAD method and by accounting for the new experimental information. To extract diffusion coefficients from the profiles, the forward-simulation analysis was applied. These coefficients were used to assess initial mobility parameters. The final parameters were obtained by directly optimizing the mobility parameters as a function of the experimental composition profiles from the diffusion couples.

The results indicate that the diffusion is influenced by impurities which are present due to the use of only nominally pure samples. The effect of typical impurities is hence incorporated in the mobility description which makes the description applicable to commercial Ti alloys.

It can be concluded that the diffusion coefficient of $V$ in $\alpha$-Ti phase decreases with increasing $\mathrm{Al}$ alloying and that 

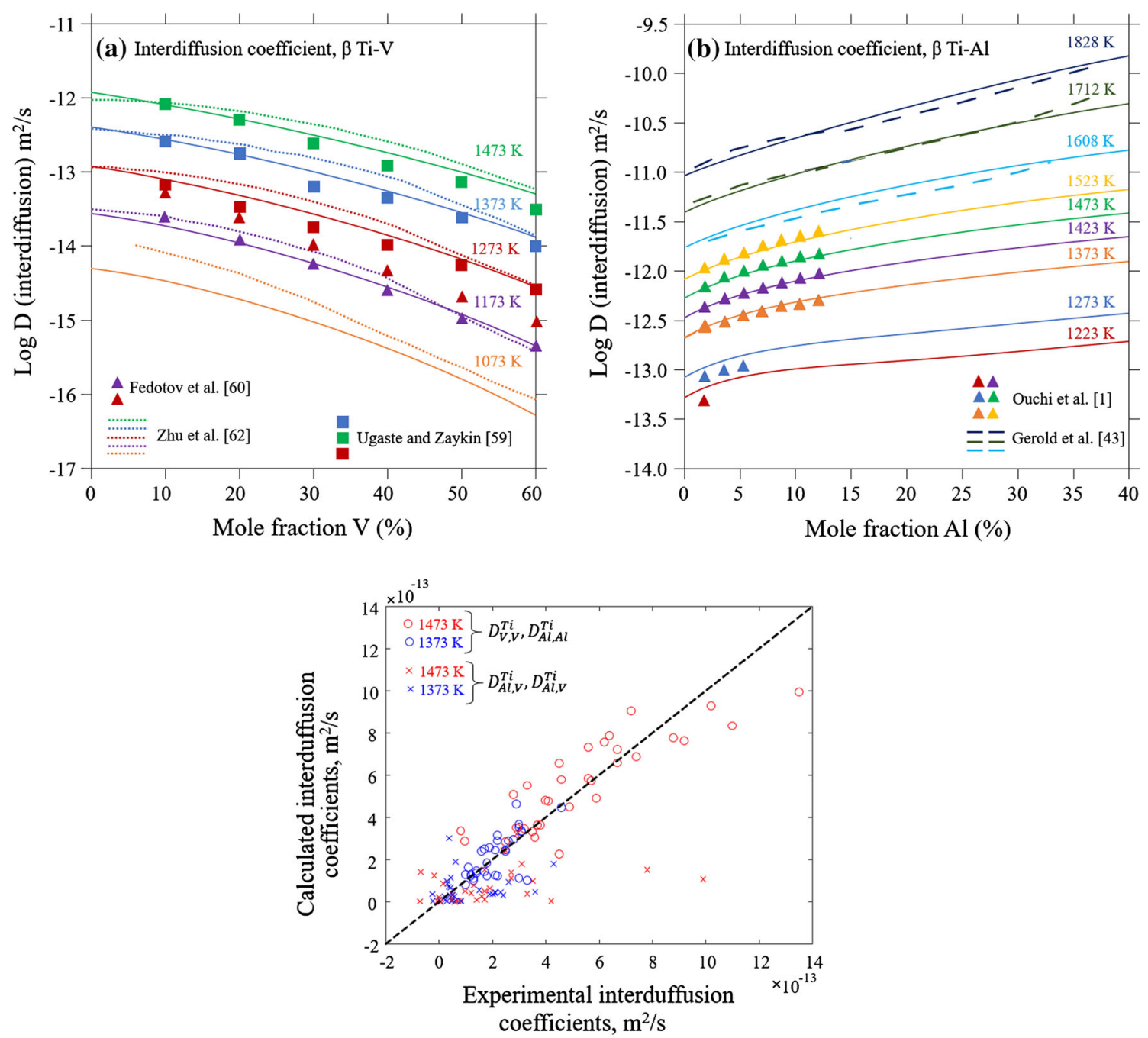

(c) Interdiffusion coefficients, $\beta$ Ti-Al-V

Fig. 11 Calculated diffusion interdiffusion coefficients (solid lines) in comparison to experimental data ${ }^{[1,61,62,64]}$ for the $\beta$ Ti-V system (a) and the $\beta$ Ti-Al system (b)
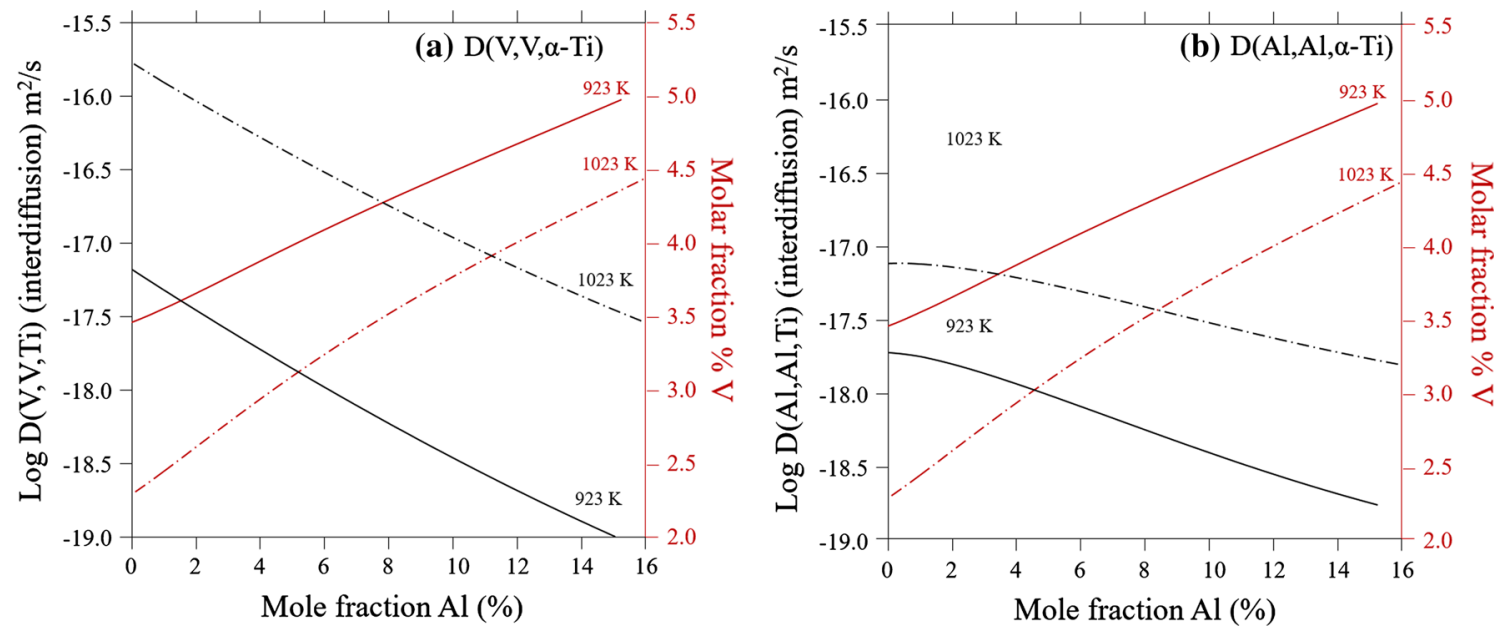

Fig. 12 Calculated main diffusion coefficients (left $y$-axis, black lines) in the ternary Ti-Al-V $\alpha$-phase: (a) $D_{V, V}^{T i}$ and (b) $D_{A l, A l}^{T i}$ as function of Al content at $923 \mathrm{~K}$ and $1023 \mathrm{~K}$. The $V$ content follows the solubility limit (right $y$-axis, red lines) (Color figure online) 
the developed diffusion mobility description reproduces this compositional effect. This information and the ability to computationally predict such effects are valuable for future Ti alloy design.

\section{Supplementary Material}

The databases (as TDB files) with both the diffusion mobility and the thermodynamic descriptions are also included as supplementary material.

Acknowledgments The authors acknowledge valuable input for the development of the thermodynamic description from Drs. Peisheng Wang and Ursula Kattner of NIST. Discussions about diffusion mobility modeling and input regarding the profile optimization module in DICTRA from Dr. Lars Höglund of KTH are greatly appreciated. The forward-simulation analysis performed at The Ohio State University was supported by the US National Science Foundation (NSF) under Grant Number CMMI-1333999, and it is a part of NSF Designing Materials to Revolutionize and Engineer our Future (DMREF) project. This publication is dedicated to Professor Zhanpeng Jin in honor of his 80th birthday.

Open Access This article is distributed under the terms of the Creative Commons Attribution 4.0 International License (http://crea tivecommons.org/licenses/by/4.0/), which permits unrestricted use, distribution, and reproduction in any medium, provided you give appropriate credit to the original author(s) and the source, provide a link to the Creative Commons license, and indicate if changes were made.

\section{References}

1. K. Ouchi, Y. Iijima, and K. Hirano, Interdiffusion in Ti-Al System, Titan, 1980, 80, p 559

2. V.V. Molokanov, D. Chernov, and P. Budberg, Solubility of Vanadium in Alpha Titanium, Met. Sci. Heat Treat., 1977, 19, p 704

3. G. Lindwall, P. Wang, U.R. Kattner, and C.E. Campbell, The Effect of Oxygen on Phase Equilbiria in the Ti-V System: Implications on Additive Manufacturing Processing of Ti Alloys. JOM , 2018, 70, p 1692

4. H. Nakajima and M. Koiwa, Diffusion in $\alpha$-Titanium, Defect Diffus. Forum, 1993, 95-98, p 775

5. G.M. Hood and R.J. Schultz, Ultra-Fast Solute Diffusion in $\alpha$-Ti and $\alpha-Z r$, Philos. Mag., 1972, 26, p 329

6. N. Chen and Z. Yu, Mechanism for Anomalously Fast Diffusion of Solute Atoms in HCP Crystals, Acta Metall. Sin., 1994, 3, p A112

7. Y. Mae, Characteristics of Matrix Metals in Which Fast Diffusion of Foreign Metallic Elements Occurs, Metall. Mater. Trans. A, 2018, 49, p 1336

8. L.J. Zhang, Z.Y. Chen, Q.M. Hu, and R. Yang, On the Abnormal Fast Diffusion of Solute Atoms in $\alpha$-Ti: A First-Principles Investigation, J. Alloys Compd., 2018, 740, p 156

9. Y. Mishin and C. Herzig, Diffusion in the Ti-Al System, Acta Mater., 2000, 48, p 589

10. M. Köppers, C. Herzig, M. Friesel, and Y. Mishin, Intrinsic SelfDiffusion and Substitutional Al Diffusion in $\alpha$-Ti, Acta Mater., 1997, 45, p 4181
11. H. Lukas, S.G. Fries, and B. Sundman, Computational Thermodynamics: The Calphad Method, Cambridge University Press, Cambridge, 2007

12. F. Zhang, A Thermodynamic and Experimental Study of the Titanium-Aluminum-Vanadium (Ti-Al-V) Ternary System, Univeristy of Wisconsin-Madison, Madison, 1997

13. B. Lindahl, X.L. Liu, Z.K. Liu, and M. Selleby, A Thermodynamic Re-assessment of Al-V Toward an Assessment of the Ternary Al-Ti-V System, Calphad, 2015, 51, p 75

14. J.C. Vickermann and I.S. Gilmore, Surface Analysis: The Principal Technique, 2nd ed., Wiley, London, 2013

15. D.E. Newbury and N.W.M. Ritchie, Performing Elemental Microanalysis with High Accuracy and High Precision by Scanning Electron Microscopy/Silicon Drift Detector EnergyDispersive X-ray Spectrometry (SEM/SDD-EDS), J. Mater. Sci., 2014, 50, p 493

16. M.J. Mengason, N.W.M. Ritchie, and D.E. Newbury, Application of standards-based quantitative EDS analysis to oxide minerals, in American Geophysical Union, Fall General Assembly 2016 (2016), p. V11B-2771

17. K.W. Moon, C.E. Campbell, M.E. Williams, and W.J. Boettinger, Diffusion in FCC Co-rich Co-Al-W Alloys at 900 and $1000^{\circ} \mathrm{C}, J$. Phase Equilibria Diffus., 2016, 37, p 402

18. J.-O. Andersson and J. Ågren, Models for Numerical Treatment of Multicomponent Diffusion in Simple Phases, J. Appl. Phys., 1992, 72, p 1350

19. A. Engström and J. Ågren, Assessment of Diffusional Mobilities in Face-Centered Cubic Ni-Cr-Al Alloys, Zeit. Metall., 1996, 87, p 92

20. B. Jönsson, Assessment of the Mobilities of $\mathrm{Cr}, \mathrm{Fe}$ and $\mathrm{Ni}$ in Binary fcc Cr-Fe and Cr-Ni Alloys, Scand. J. Metall., 1995, 24, p 21

21. B. Jönsson, Assessment of the Mobilities of $\mathrm{Cr}, \mathrm{Fe}$ and $\mathrm{Ni}$ in bcc Cr-Fe-Ni Alloys, ISIJ Int., 1995, 35, p 1415

22. B. Jönsson, Assessment of the Mobilities of $\mathrm{Cr}, \mathrm{Fe}$, and $\mathrm{Ni}$ in fcc Cr-Fe-Ni Alloys, Zeit. Metall., 1995, 86, p 686

23. H. Larsson, T. Jonsson, R. Naraghi, Y. Gong, R.C. Reed, and J. Ågren, Oxidation of Iron at $600^{\circ} \mathrm{C}$ : Experiments and Simulations. Mater. Corros., 2016, 30, p 133

24. O. Redlich and A.T. Kister, Algebraic Representation of Thermodynamic Properties and the Classification of Solutions, Ind. Eng. Chem. Res., 1948, 40, p 345

25. J. Askill, Tracer Diffusion Data for Metals, Alloys, and Simple Oxides, Springer, Berlin, 2012

26. J. Xin, Y. Du, S. Shang, S. Cui, J. Wang, B. Huang, and Z. Liu, A New Relationship Among Self- and Impurity Diffusion Coefficients in Binary Solution Phases, Metall. Mater. Trans. A, 2016, 47, p 3295

27. C.E. Campbell, A New Technique for Evaluating Diffusion Mobility Parameters, J. Phase Equilibria Diffus., 2005, 26, p 435

28. L. Boltzmann, Zur Integration der Diffusionsgleichung bei variabeln Diffusionscoefficienten, Ann. Phys., 1894, 289, p 959

29. C. Matano, On the Relation Between the Diffusion-Coefficients and Concentrations of Solid Metals (The Nickel-Copper System), Jpn. J. Phys, 1933, 8, p 109

30. F. Sauer and V. Freise, Diffusion in binären Gemischen mit Volumenänderung, Zeit. Elektrochem., 1962, 66, p 353

31. L.D. Hall, An Analytical Method of Calculating Variable Diffusion Coefficients, J. Chem. Phys., 1953, 21, p 87

32. Q. Zhang and J.C. Zhao, Extracting Interdiffusion Coefficients from Binary Diffusion Couples Using Traditional Methods and a Forward-Simulation Method, Intermetallics, 2013, 34, p 132

33. Q. Zhang, Z. Chen, W. Zhong, and J.C. Zhao, Accurate and Efficient Measurement of Impurity (Dilute) Diffusion Coefficients Without Isotope Tracer Experiments, Scr. Mater., 2017, 128, p 32 
34. W.J. Boettinger, M.E. Williams, K.W. Moon, G.B. McFadden, P.N. Patrone, and J.H. Perepezko, Interdiffusion in the Ni-Re System: Evaluation of Uncertainties, J. Phase Equilibria Diffus., 2017, 38, p 750

35. C.E. Campbell, W.J. Boettinger, and U.R. Kattner, Development of a Diffusion Mobility Database for Ni-Base Superalloys, Acta Mater., 2002, 50, p 775

36. J.-O. Andersson, T. Helander, L. Höglund, P. Shi, and B. Sundman, Thermo-Calc \& DICTRA, Computational Tools for Materials Science, Calphad, 2002, 26, p 273

37. M. Köppers, D. Derdau, M. Friesel, and C. Herzig, Self-Diffusion and Group III (Al, Ga, In) Solute Diffusion in hcp Titanium, Defect Diffus. Forum, 1997, 143-147, p 43

38. J. Räisänen, A. Anttila, and J. Keinonen, Diffusion of Aluminum in Ion-Implanted $\alpha$-Ti, J. Appl. Phys., 1985, 57, p 613

39. C. Herzig, R. Willecke, and K. Vieregge, Self-Diffusion and Fast Cobalt Impurity Diffusion in the Buld and in Grain Boundaries in Hexagonal Titanium, Philos. Mag. A, 1991, 63, p 949

40. L.L. Araújo and M. Behar, Al and Ag Diffusion Study in $\alpha$ Titanium, Appl. Phys. A, 2000, 174, p 169

41. W.W. Xu, S.L. Shang, B.C. Zhou, Y. Wang, L.J. Chen, C.P. Wang, X.J. Liu, and Z.K. Liu, A First-Principles Study of the Diffusion Coefficients of Alloying Elements in Dilute $\alpha$-Ti Alloys, Phys. Chem. Chem. Phys., 2016, 18, p 16870

42. S.-L. Shang, B.-C. Zhou, W.Y. Wang, A.R. Ross, X.L. Liu, H. Fang, Y. Wang, and Z.-K. Liu, A Comprehensive First-Principles Study of Pure Elements: Vacancy Formation and Migration Energies and Self-Diffusion Coefficients, Acta Mater., 2016, 109, p 128

43. L. Huang, Y. Cui, H. Chang, H. Zhong, J. Li, and L. Zhou, Assessment of Atomic Mobilities for bcc Phase of Ti-Al-V System, J. Phase Equilibria Diffus., 2010, 31, p 135

44. D. Goold, Diffusion in Aluminium, Tin, Vanadium, Molybdenum, and Manganese in Titanium, J. Inst. Met., 1959, 88, p 444

45. U. Gerold and C. Herzig, Titanium Self-Diffusion and Chemical Diffusion in bcc Ti-Al Alloys, Defect Diffus. Forum, 1997, 143-147, p 437

46. H. Araki, T. Yamane, Y. Minamino, S. Saji, Y. Hana, and S.B. Jung, Anomalous Diffusion of Aluminum in $\beta$-Titanium, Metall. Mater. Trans. A, 1994, 25, p 874

47. R. Kainuma and G. Inden, Interdiffusion in the Ti-rich Phases of the Ti-Al System, Zeit. Metall., 1997, 88, p 429

48. W. Li, B. Tang, Y.W. Cui, R. Hu, H. Chang, J. Li, and L. Zhou, Assessment of Diffusion Mobility for the bcc Phase of the TiAlCr System, Calphad, 2011, 35, p 384

49. Y. Chen, B. Tang, G. Xu, C. Wang, H. Kou, J. Li, and Y. Cui, Diffusion Research in BCC Ti-Al-Mo Ternary Alloys, Metall. Mater. Trans. A, 2014, 45, p 1647

50. Y. Chen, J. Li, B. Tang, H. Kou, J. Segurado, and Y. Cui, Computational Study of Atomic Mobility for bcc Phase in Ti-AlFe System, Calphad, 2014, 46, p 205

51. T.S. Lundy and C.J. Mcharguet, Diffusion of V48 in Vanadium, Trans. Met. Soc. AIME, 1965, 233, p 243

52. R.F. Peart, Diffusion of V48 and Fe59 in Vanadium, J. Phys. Chem. Solids, 1965, 26, p 1853

53. R.P. Agarwala, S.P. Murarka, and M.S. Anand, Diffusion of Vanadium in Niobium, Zirconium and Vanadium, Acta Metall., 1968, 16, p 61

54. J. Pelleg, Self Diffusion in Vanadium Single Crystals, Philos. Mag., 1974, 29, p 383
55. M.P. Macht, G. Frohberg, and H. Wever, Self Diffusion of Vanadium, Zeit. Metall., 1979, 70, p 209

56. D. Ablitzer, J.P. Haeussler, and K.V. Sathyaraj, Vanadium SelfDiffusion in Pure Vanadium and in Dilute Vanadium-Iron and Vanadium-Tantalum Alloys, Philos. Mag. A, 1983, 47, p 515

57. J.F. Tiers and Y. Chabre, High-Temperature Nuclear Spin Relaxation in $51 \mathrm{~V}$ Metal: Self-Diffusion and Interstitial-Impurity Diffusion Effects, J. Phys. F Met. Phys., 1981, 11, p 1943

58. B. Gunther and O. Kanert, Nuclear Magnetic Resonance Study of Atomic Motions in Vanadium, Acta Metall., 1983, 31, p 909

59. J.F. Murdock, T.S. Lundy, and E.E. Stansbury, Diffusion of Ti44 and V48 in Titanium, Acta Metall., 1964, 12, p 1033

60. J.F. Murdock and C.J. Mcharguet, Self-Diffusion in Body-Centered Cubic Titanioum-Vanadium Alloys, Acta Metall., 1968, 16, p 493

61. Y.E. Ugaste and Y.A. Zajkin, Investigation of Mutual Diffusion in Titanium-Vanadium and Titanium-Niobium System, Fiz. Met. Met., 1975, 40, p 567-575

62. S.G. Fedotov, M.G. Chudinov, and K.M. Konstantinov, Mutual Diffusion in the Systems Ti-V, Ti-Nb, Ti-Ta and Ti-Mo, Fiz. Met. Met., 1969, 25, p 111

63. W. Sprengel, T. Yamada, and H. Nakajima, Interdiffusion in Binary $\beta$-Titanium Alloys, Defect Diffus. Forum, 1997, 143-147, p 431

64. L. Zhu, Q. Zhang, Z. Chen, C. Wei, G.M. Cai, L. Jiang, Z. Jin, and J.C. Zhao, Measurement of Interdiffusion and Impurity Diffusion Coefficients in the bcc Phase of the Ti-X (X = Cr, Hf, Mo, Nb, V, Zr) Binary Systems Using Diffusion Multiples, J. Mater. Sci., 2017, 52, p 3255

65. T. Takahashi, Y. Minamino, and M. Komatsu, Interdiffusion in Beta Phase of the Ternary Ti-Al-V System, Nippon Kinzoku Gakkaishi/J. Jpn. Inst. Met., 2008, 72, p 1044

66. S.L. Semiatin, T.M. Brown, T.A. Goff, P.N. Fagin, D.R. Barker, R.E. Turner, J.M. Murry, J.D. Miller, and F. Zhang, Diffusion Coefficients for Modeling the Heat Treatment of Ti-6Al-4V, Metall. Mater. Trans. A, 2004, 35A, p 3015

67. H. Wang, N. Warnken, and R.C. Reed, Thermodynamic and Kinetic Modeling of bcc Phase in the Ti-Al-V Ternary System, Mater. Sci. Eng. A, 2010, 528, p 622

68. Q. Chen, N. Ma, K. Wu, and Y. Wang, Quantitative Phase Field Modeling of Diffusion-Controlled Precipitate Growth and Dissolution in Ti-Al-V, Scr. Mater., 2004, 50, p 471

69. M.A. Dayananda, An Analysis of Concentration Profiles for Fluxes, Diffusion Depths, and Zero-Flux Planes in Multicomponent Diffusion, Metall. Trans. A, 1983, 14, p 1851

70. T. Takahashi, Y. Minamino, and M. Komatsu, Interdiffusion in $\beta$ Phase of the Ternary Ti-Al-V System, Mater. Trans., 2008, 49, p 125

71. A. Dima, S. Bhaskarla, C. Becker, M. Brady, C. Campbell, P. Dessauw, R. Hanisch, U. Kattner, K. Kroenlein, M. Newrock, A. Peskin, R. Plante, S.Y. Li, P.F. Rigodiat, G.S. Amaral, Z. Trautt, X. Schmitt, J. Warren, and S. Youssef, Informatics Infrastructure for the Materials Genome Initiative, JOM, 2016, 68, p 2053

72. Y.W. Cui, K. Oikawa, R. Kainuma, and K. Ishida, Study of Diffusion Mobility of Al-Zn Solid Solution, J. Phase Equilibria Diffus., 2006, 27, p 333

73. A.T. Dinsdale, SGTE Data for Pure Elements, Calphad, 1991, 15, p 317 